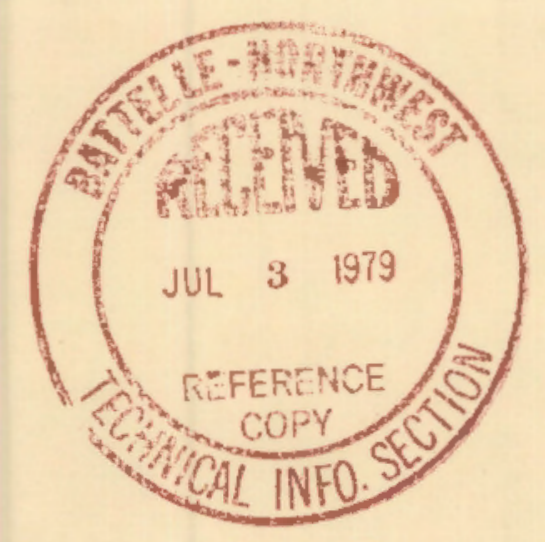

Estimate of Feasibility to Develop

Acoustic Emission-Flaw

Relationships for Inservice

Monitoring of

Nuclear Pressure Vessels
P. H. Hutton
E. B. Schwenk
R. J. Kurtz

April 1979

Prepared for

the U.S. Nuclear Regulatory Commission

Pacific Northwest Laboratory

Operated for the U.S. Department of Energy

by Battelle Memorial Institute 


\title{
NOTICE
}

This report was prepared as an account of work sponsored by the United States Government. Neither the United States nor the United States Nuclear Regulatory Commission, nor any of their employees, nor any of their contractors, subcontractors, or their employees, makes any warranty, express or implied, or assumes any legal liability or responsibility for the accuracy, completeness or usefulness of any information, apparatus, product or process disclosed, or represents that its use would not infringe privately owned rights.

\author{
PACIFIC NORTHWEST LABORATORY \\ operated by \\ BATTELLE \\ for the \\ UNITED STATES DEPARTMENT OF ENERGY \\ Under Contract EY-76-C-06-1830
}

\author{
Printed in the United States of America \\ Available from \\ National Technical Information Service \\ United States Department of Commerce \\ 5205 Port Royal Road \\ Springfield, Virginia 22151
}

Price: Primted Copy \$__

NTIS

-Pager Selling Price

001-025 $\quad 24.00$

025-050 $\quad 5.50$

35.25

$076-100 \quad \$ 6.00$

$101-125 \quad \$ 6.50$

$126-150 \quad \$ 7.25$

$151-175$

$176-200 \quad 59.00$

$201-225 \quad 59.25$

$226-250 \quad 59.50$

251- Z75 $\$ 10.75$

206-300 $\$ 11.00$ 
NUREG/CR - 0800

PNL - 2977

ESTIMATE OF FEASIBILITY TO DEVELOP ACOUSTIC EMISSION--FLAW RELATIONSHIPS FOR INSERVICE

MONITORING OF NUCLEAR PRESSURE VESSELS

P. H. Hutton

E. B. Schwenk

R. J. Kurtz

April 1979

Prepared for

the U.S. Nuclear Regulatory Commission under a Related Services Agreement

with the U.S. Department of Energy

Contract EY-76-C-06-1830

FIN N0. B2088

Pacific Northwest Laboratory

Richland, Washington 99352 
, 


\section{ESTIMATE OF FEASIBILITY TO DEVELOP \\ ACOUSTIC EMISSION--FLAW RELATIONSHIPS FOR \\ INSERVICE MONITORING OF NUCLEAR PRESSURE VESSELS}

\section{EXECUTIVE SUMMARY}

The work presented in this report is part of an ongoing program at Pacific Northwest Laboratory to determine the feasibility of continuous inservice monitoring of nuclear pressure vessels, using acoustic emission (AE) to detect and evaluate growing flaws. The work is sponsored by the Reactor Safety Research Division of the United States Nuclear Regulatory Commission. The major program objectives are to:

- develop criteria to distinguish flaw growth AE from nonsignificant acoustic signals

- develop an AE/flaw growth model as a basis for relating inservice AE to flaw significance

- demonstrate application of program results through both off-reactor and on-reactor testing.

This work was initiated in July 1976, with most of the preliminary activity aimed at developing appropriate AE measurement methods. Subsequent emphasis was placed on developing AE/flaw relationships, which is one of the major program objectives.

To fulfill the program objectives, laboratory fracture mechanics tests have been performed. These tests were designed to determine the effect of variables such as microstructure, flaw geometry, temperature and mechanical loading upon the $A E$ response during increasing flaw severity. Future tests will more fully simulate reactor pressure vessel behavior.

From these tests, two empirical models have been developed to relate $\mathrm{AE}$ to fatigue crack growth. One model relates rate of change of AE to stress intensity factor range or the crack growth rate. The other model relates 
total accumulated $A E$ to stress intensity factor. Both of these are still preliminary models that need refinement. They do, however, demonstrate for 14 variations in material, geometry and temperature (collectively) a consistent increase in $A E$ associated with increasing flaw severity. The results thus far are encouraging and we conclude that there is a high potential for achieving the goal of detecting and evaluating flaw growth in a reactor pressure vesse] by continuous $A E$ monitoring.

Further assessment of feasibility hinges upon the results of tests designed to more fully simulate the reactor pressure vessel. These tests (to be performed during the latter half of FY-79 and FY-80) will consist of experiments incorporating heavy section material and include environmental factors such as high-temperature and high-pressure water in contact with a growing crack. 


\section{CONTENTS}

EXECUTIVE SUMMARY

ij $i$

FIGURES

vi

TABLES

INTRODUCTION

SUMMARY

TEST RESULTS AND ANALYSIS

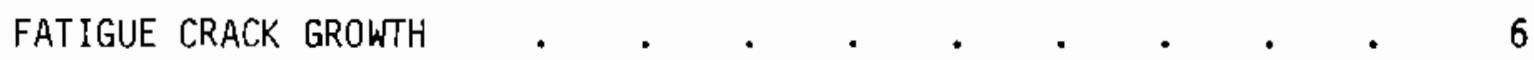

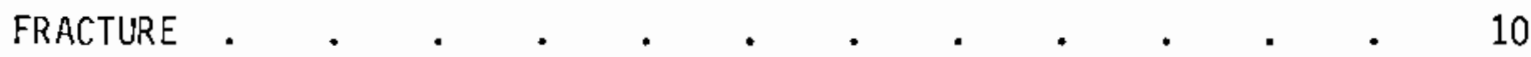

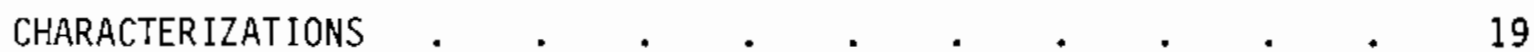

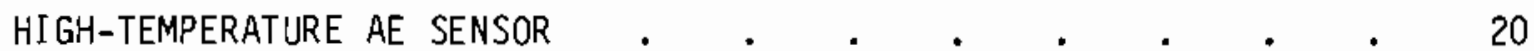

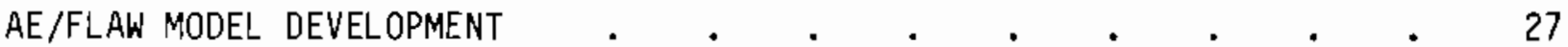

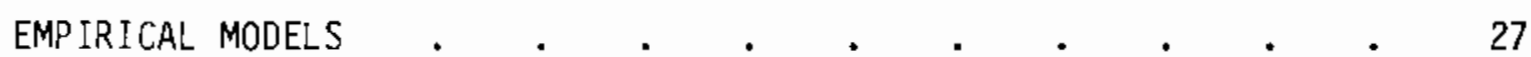

THEORETICAL MODELS . . . . . . . . . . . . . . . . . . 29

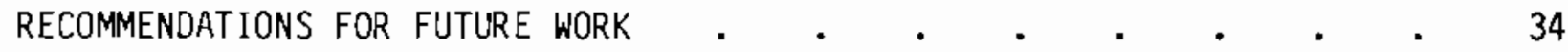

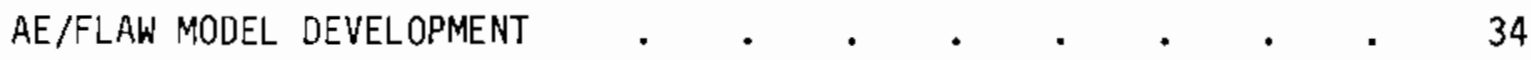

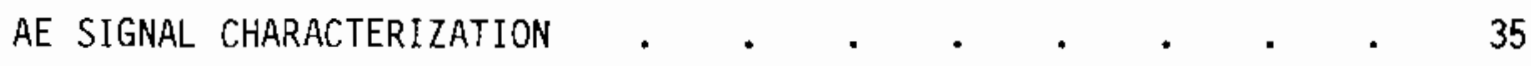

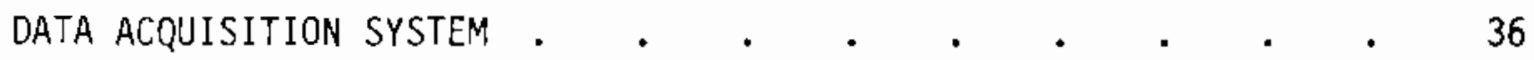

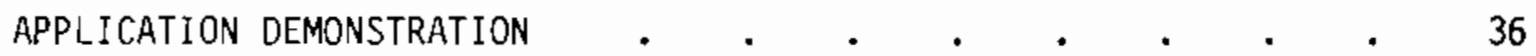

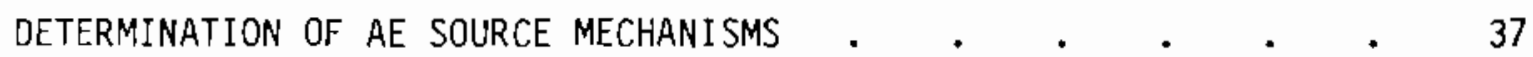

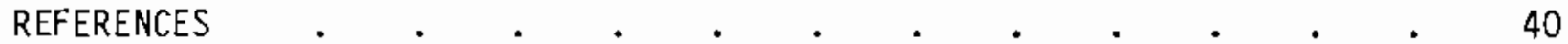




\section{FIGURES}

1. Fatigue Crack Growth Rate (da/dn) Versus Stress Intensity

Factor Range ( $\mathrm{K}$ ) for Three Fatigue Spec imens, $\mathrm{R}=0.1,3 \mathrm{~Hz}$. $\quad .8$

2. AE Rate Versus Fatigue Crack Growth Rate for SEN Type Specimens . 8

3. AE Rate Versus Fatigue Crack Growth Rate for 2T-CT Type Specimens 9

4. AE Rate Versus Fatigue Crack Growth Rate for

$N$ Type Specimens $(R=0.1)$. . . . . . . . . . 10

5. AE Rate Versus Fatigue Crack Growth Rate for

SEN,2T-CT, and SN Type Specimens . . . . . . . . . 11

6. Fracture Test B2-1B Data--Base Metal . . . . . . 13

7. Fracture Test B2-3A Data--Weld Metal . . . . . . 13

8. Fracture Test B2-3B Data--Base Metal . . . . . . 14

9. Load, COD and $A E$ Event Count Versus Tíme, Specimen . . . . 14 $1-2 A-2 B$, Room Temperature

10. Load and AE Event Count Versus COD, SEN Specimen 1-2A-6B, 550 .15

11. Load and AE Event Count Versus COD, SN Specimen . . . . 15 $2-1 A-2 B$, Room Temperature

12. Load and AE Event Count Versus COD, SN Specimen 1-2A-4A, 5500F . 16

13. Sunmation $A E$ Versus $K$ for Vessei $V 7-B$ and $V 8$. . . . . 16

14. Sunmation $A E$ Versus $C O D$ for Vessel $V 7-B$ and $V 8$. . . 17

15. Crack Growth and AE Versus Load Cycles for Fatigue Crack Growth in Air and Water. . . . . . . . . 17

16. AE Count and Load Data Versus Time for DCB Specimen 1-2A-5A-4 Following a Six-Week Exposure in Room Temperature

Distilled Water . . . . . . . . . .

17. AE Count and Loading Range Data Versus Total Load Cycles for DCB Specimen 1-2A-5A-4 Following a Six-Week Exposure in Room Temperature Distilled Water . . . . .

18. High Temperature Sensor Response to a Constant Pulse Input to Test Plate Measured at 550 $\mathrm{F}$. . . . . . 


\section{FIGURES (cont'd)}

19. High Temperature Sensor Response to a Constant Pulse Input

to Test Plate Measured at Room Temperature . . . . . 23

20. High Temperature Sensor Response to a Constant Pulse Input to Test Plate Measured at 550 $\mathrm{F}$. . . . . . . 24

21. Composite AE Event Count Rate Versus K Curves, Room Temperature and 550\% . $\quad . \quad$. . . . . . . 28

22. Summation AE Event Count Versus K, Specimen 1-2A-6B, 550.$\quad$. 28 


\section{$\underline{\text { TABLES }}$}

1. Sumary of Fatigue Crack Growth Test Conditions for A533B CI 1 Steel 7

2. Summary of Fracture Test Conditions for A533B CI 1 Steel . . 12

3. Signal-to-Noise Ratio for High-Temperature Sensors . . . . 26

4. Summary of AE-FCG Rate and Summation Analyses or Several Specimen Geometries and Material Conditions . . . . . . 32 


\section{ESTIMATE OF FEASIBILITY TO DEVELOP \\ ACOUSTIC EMISSION--FLAW RELATIONSHIPS FOR \\ INSERVICE MONITORING OF NUCLEAR PRESSURE VESSELS}

\section{INTRODUCTION}

The purpose of this program is to evaluate the feasibility of detecting and analyzing flaw growth in reactor pressure boundaries by continuously monitoring for acoustic emission (AE). Major program objectives are:

- develop criteria to distinguish flaw growth AE from nonsignificant acoustic signals

- develop an $A E / f l a w$ growth model as a basis for relating inservice $A E$ to flaw significance

- demonstrate application of program results through both off-reactor and on-reactor testing.

The program was initiated in July 1976. One of the identified requirements is an evaluation of feasibility of achieving the program objectives based on results through $F y-78$. This report presents that evaluation and recommends additionai investigation required. The time period covered has been extended into FY-79 to permit including important test results. 


\section{SUMMARY}

To fulfill the program objectives, laboratory fracture mechanics tests have been performed. These tests were designed to determine the effect of variables such as microstructure, flaw geometry, temperature and mechanical loading upon the $A E$ response during increasing flaw severity. The results of these tests consistently show that an increased $A E$ response is associated with increasing flaw severity. Thus, we conclude that there is a high potential for achieving the goal of detecting and evaluating flaw growth in a reactor pressure vessel by continuous AE monitoring.

Achieving the potential of detecting and evaluating flaw growth in a reactor pressure vessel depends upon two major factors: first, consistent relationships between flaw severity and measurable AE parameters and, second, a data acquisition system suitable for long term exposure to a reactor environment.

The first factor includes characterization of significant $A E$ and development of an $A E / f l a w$ growth model (the first two program objectives). Primary emphasis has been on developing an AE/flaw growth model using laboratory fracture mechanics scoping tests.

Two major mechanical loading conditions were considered for the preliminary scoping tests on $A 533 B$ material. The first was associated with the assumption that fatigue crack growth (FCG) is the primary mechanism whereby flaws grow in a pressure vessel during service. Secondly, it was decided that transient loading conditions should be considered if the approach was to have application to, for example, off-normal reactor operation. Hence, laboratory FCG and fracture (rising load) testing were incorporated into the program. The parameters for FCG and fracture tests on A533B material have been monitored for $A E$ at room temperature and $550^{\circ} \mathrm{F}$ in air. Three laboratory specimen configurations were used to gather the appropriate information: 1) single edge notch (SEN)-through, wa11,2) part-through wall surface notch (SN), and 3) compact tension (CT)-through wall. 
The $A E$ results from these tests and the results from two heavy section steel technology (HSST) pressure vessel tests (6 in. wall thickness) were compared to assess the potential feasibility of using AE to monitor flaw growth in nuclear pressure vessels. In general, AE increased with flaw severity for all tests. Most of the AE response from SEN defect fracture tests occurred after maximum load was reached; hence, the majority of the AE probably occurred from ductile crack extension during mechanical instability. The data from the SN defect fracture tests at room temperature and $550^{\circ} \mathrm{F}$ correlated well in form with the HSST pressure vessel tests at $-5^{\circ}$ and $200^{\circ} \mathrm{F}$, and the $A E$ response appeared to be independent of temperature over the temperature ranges tested. The SN defect laboratory fracture tests and the HSST tests were philosophically similar in that both employed part-through wall defects and they were mechanically loaded in a similar manner.

The laboratory FCG tests with both SEN and SN defects showed a temperature effect. Crack growth rates at $550^{\circ} \mathrm{F}$ for the SEN defects were between $55 \%$ and $75 \%$ higher than at room temperature for the same stress intensity factor range $(\Delta K)$; but the $A E$ produced per cycle for the same crack growth rate appears to be less for the higher temperature. The limited SN data were similar to the SEN results.

A limited number of results were obtained from CT specimens fabricated out of base and weld metal. The microstructural difference between the two specimens did not yield a significant difference in the $A E$ behavior at room temperature.

One slag inclusion test was performed giving an AE response 4-1/2 times larger than that of a control sample. However, the results were inconclusive to distinguish slag cracking from metal cracking $A E$ within the scope of the parameters measured. This may be due to the relative smallness of the slag inclusion and incomplete fusion associated with the specimen weld.

Four available high-temperature AE sensors have been tested for $2830 \mathrm{hr}$ exposure at $500^{\circ}$ to $550^{\circ} \mathrm{F}$ in air with week ly cycling to room temperature. Results show that two sensors (a metal waveguide and a direct surface contact sensor) can withstand high-temperature environment for an extended period. 
One $A E$ characterization test was completed which showed a decrease in $A E$ (particularly high-amplitude signals) upon immersion of the specimen in water. The reason for this effect is being investigated. This same specimen was used to investigate the effects of an oxide on the crack surface. When compared to $A E$ from $F C G$ in the same specimen prior to oxidation, the "oxide data" showed a higher AE rate than data obtained from unoxidized specimens until the fatigue crack front moved away from the oxidized fracture surface. At this point, the $A E$ rate returned to levels similar to that obtained prior to oxidation.

The successful application of $A E$ to pressure vessel monitoring depends upon consistent relationships between flaw severity and measurable AE parameters. Two empirical models have been developed to relate AE to FCG. One model relates rate of change of $A E$ to $\triangle K$ or the crack growth rate $(\mathrm{da} / \mathrm{dn})$. The other mode? relates total accumulated $A E$ to $K$. Both of these are still preliminary models that need refinement. They do, however, demonstrate for 14 variations in material, geometry and temperature (collectively) a consistent increase in $\mathrm{AE}$ associated with an increasing flaw severity. In addition, three theoretical models based upon linear elastic fracture mechanics were compared against the FCG resuits obtained from several different specimens. Only limited promise with such models was found. Room temperature SEN-FCG data correlated with plastic zone area and crack area modeis, while CT data correlated with the plastic zone volume model. The $550^{\circ} \mathrm{F}$ data could not be correlated with any of the three theoretical models.

Analysis of measured AE signal parameters--energy, peak-time, amplitude, and first half-cycle polarity--has not shown clear AE signal characterization. Very preliminary results using pattern recognition techniques are encouraging.

The overall results thus far are favorable and the program objectives appear feasible and practical. We believe that continuing research is necessary in the following areas to achieve program objectives: 
1. Continued development and verification of the $A E / f l$ aw model through further investigation of the influence of load cycle rate, R-ratio, simulated service loading, material volume, flaw geometry, temperature, and water on $A E$ in flawed heavy section material.

2. Development of $A E$ signal characterization through more rigorous analysis of the $A E$ signal waveform including such parameters as energy, a modified measure of peak-time and amplitude during FCG, and time location of the $A E$ signal with respect to the load waveform (a new parameter). Pattern recognition techniques need to be further investigated as a potential method of $A E$ signal identification.

3. Continued development of data acquisition methodology through $A E$ sensor testing in a true reactor environment.

4. Design of an optimized on-reactor $A E$ data acquisition system.

5. Design of a methodology for application of an interpretive model in the field. 


\section{TEST RESULTS AND ANALYSIS}

FATIGUE CRACK GROWTH

A number of $F C G$ tests of $A 533 B$ base and weld metal have been performed at room temperature and $550^{\circ} \mathrm{F}$ and monitored for $\mathrm{AE}$. Several specimen geometry and material property variations have been investigated. A summary of the FCG conditions employed is given in Table 1 . The fatigue crack growth rate (da/dn) versus stress intensity factor range $(\Delta K)$ data for three room temperature tests are plotted in Figure 1 . Within the range of normal experimental scatter, all of the room temperature $d a / d n$ versus $\Delta K$ data fell on the same curve. The $550^{\circ} \mathrm{F}$ crack growth rate was between $55 \%$ and $75 \%$ higher than the room temperature crack growth rate for the same $\Delta K$ level (dashed line in Figure 1 , no data points included).

In general, AE-FCG data from all specimens behaved consistently. The rate of change of $A E$ increased with increases in either da/dn or $\triangle K$. Plots of the $A E$ event count rate (counts/cycle, $d N / d n$ ) versus da/dn are given in Figures 2 to 5 .

The SEN results plotted in Figure 2 show the effects of temperature and prior plastic strain upon the AE data rate. While the $550^{\circ} \mathrm{F}$ data represent only one specimen, increasing temperature appears to decrease the amount of $A E$ produced per cycle for the same $\mathrm{da} / \mathrm{d} n$.

Limited experimental work on the effect of $R$ ratio $\left(R=P_{\min } / P_{\max }\right)$ was obtained during the $550^{\circ} \mathrm{F} \mathrm{FCG} \mathrm{test.} \mathrm{The} \mathrm{results} \mathrm{(Figure} \mathrm{2)} \mathrm{are} \mathrm{inconclusive}$ as to the effect of $\mathrm{R}$ ratio at $550^{\circ} \mathrm{F}$, since they fall within the SEN-FCG data scatter band. SEN specimen 1-1A-2A was longitudinally prestrained. Again, the results do not illustrate a distinctive effect since they fall within the general data scatter band.

Results obtained from compact tension (2T-CT) specimens fabricated from base and weld metal are plotted in Figure 3 . The microstructural difference between the two specimens did not produce a significant difference in the $\mathrm{AE}$ rate behavior. 
TABLE 1. Summary of Fatigue Crack Growth Test Conditions for A533B CI 1 Steel

\begin{tabular}{|c|c|c|c|c|c|c|c|c|}
\hline $\begin{array}{c}\text { Specimen } \\
\text { No. } \\
\end{array}$ & $\begin{array}{l}\text { Specimen } \\
\text { Type } \\
\end{array}$ & $\begin{array}{c}\text { Thickness, } \\
\text { in. } \\
\end{array}$ & $\begin{array}{l}\text { Test } \\
\text { Temp, }{ }^{\circ} \mathrm{F} \\
\end{array}$ & $\begin{array}{l}\text { Material } \\
\text { Condition } \\
\end{array}$ & R Ratio & Rate, $\mathrm{Hz}$ & $\begin{array}{c}\text { AE System } \\
\text { Sensitivity, } \mu \text { bar }\end{array}$ & Comments \\
\hline$B 2-1 B$ & 2T-CT & 1.75 & RT & $B M^{(a)}$ & 0.1 & 3 & 0.11 & \multirow{6}{*}{$\begin{array}{l}\text { 3\% Prestrain } \\
3 \text { Pt. Bend } \\
\text { Straightened }\end{array}$} \\
\hline$B 2-1 A$ & 2T-CT & 1.75 & RT & $\mathbb{W M}^{(b)}$ & 0.1 & 3 & 0.09 & \\
\hline $1-1 A-2 A$ & SEN & 0.5 & RT & BM & 0.1 & $1-4$ & \multirow{4}{*}{$\begin{array}{l}0.08 \\
0.11 \\
0.11 \\
0.9\end{array}$} & \\
\hline $1-2 A-1 B$ & SEN & 1.0 & RT & $B M$ & 0.1 & $2-3$ & & \\
\hline $1-2 A-2 B$ & SEN & 1.0 & RT & BM & 0.1 & $3-10$ & & \\
\hline $1-2 A-6 B$ & SEN & 1.0 & 550 & $B M$ & $0.1,0.5$ & $2-3$ & & \\
\hline $2-1 A-2 B$ & SN & 1.0 & RT & $B M$ & 0.1 & $1-2$ & 0.11 & \multirow{2}{*}{$\begin{array}{l}3 \text { Pt. Bend } \\
\text { Straightened }\end{array}$} \\
\hline $1-2 A-6 A$ & SN & 1.0 & $R T, \quad 550$ & BM & 0.1 & 1 & 0.12 & \\
\hline
\end{tabular}

(a) $B M=$ Base Metal
(b) WM $=$ Weld Metal 


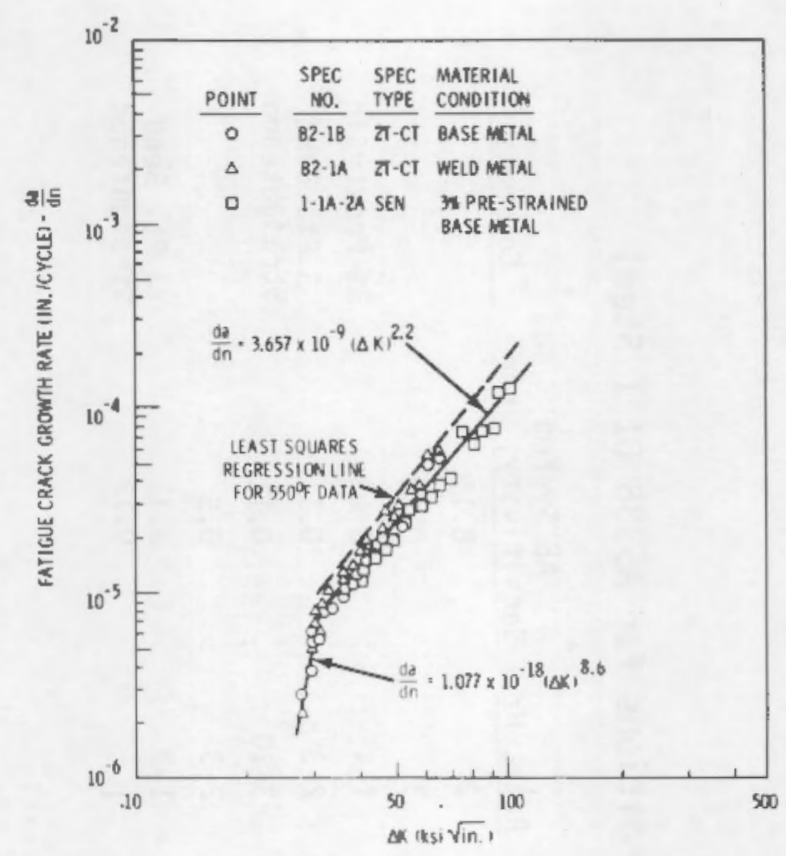

FIGURE 1. Fatigue Crack Growth Rate (da/dn) Versus Stress Intensity Factor Range $(\Delta K)$ for Three Fatigue Specimens $(\mathrm{R}=0.1,3 \mathrm{~Hz})$

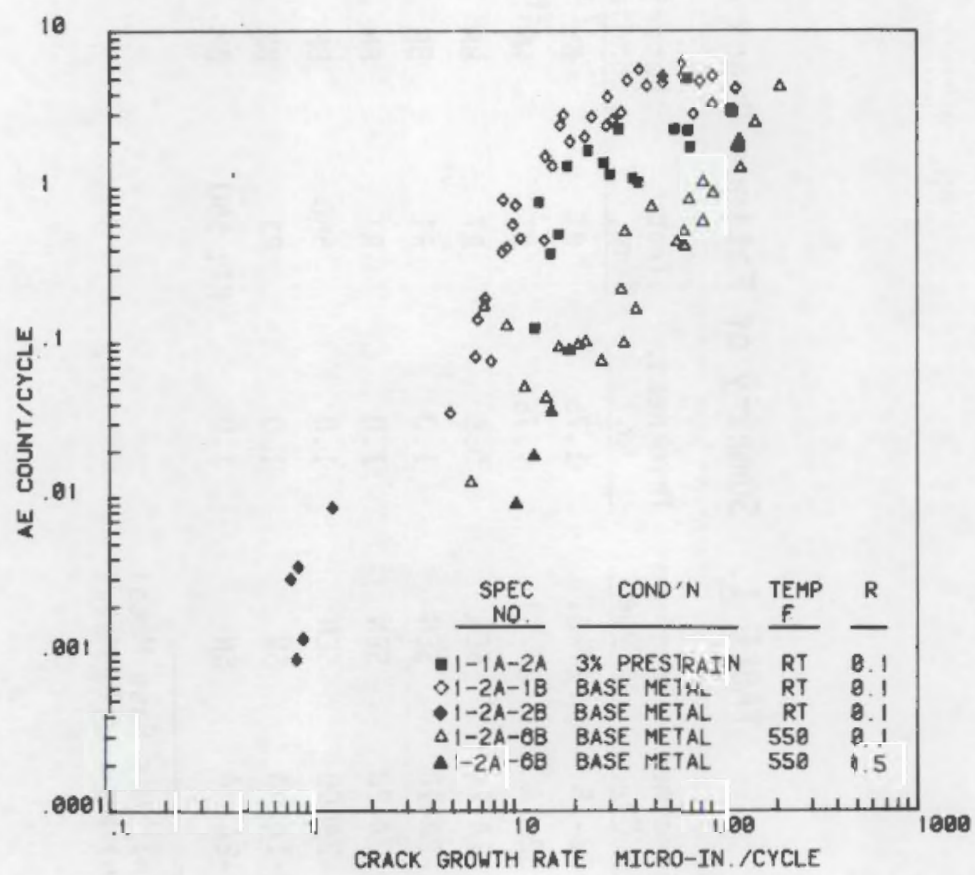

FIGURE 2. AE Rate Versus Fatigue Crack Growth Rate for SEN Type Specimens 


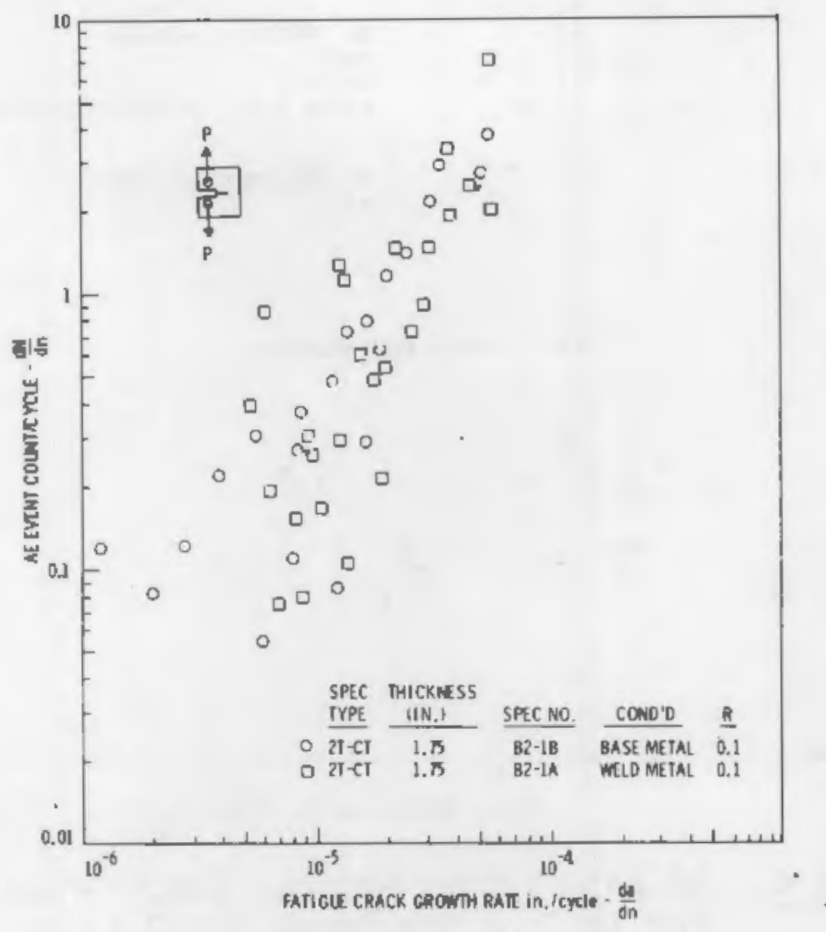

FIGURE 3. AE Rate Versus Fatigue Crack Growth Rate for 2T-CT Type Specimens

Experimental data obtained during room temperature and $550^{\circ} \mathrm{F}$ FCG of two SN specimens are plotted in Figure 4. The effect of temperature on the AE rate was not as definite as for the SEN defect specimens, but the same genera1 trend appears. Note that the $A E$ rate drops off markedly as the net section stress approaches the $550^{\circ} \mathrm{F}$ yield strength. This effect has also been observed on the room temperature SEN-FCG tests. (1)

Another interesting effect observed during room temperature FCG testing of SN specimen 1-2A-6A was the apparent initially decreasing AE rate with increasing da/dn. This may have been due to buildup of oxide on the fatigue crack fracture surfaces resulting from the abnormal test sequence applied to this specimen. The specimen was notched and fatigue cycled just long enough to initiate a fatigue crack. Then, because of other program demands upon the AE monitoring equipment, the specimen was set aside for several months. During that time, the notch was covered, but not sealed from the laboratory atmosphere. Thus, oxidation of the fatigue crack fracture surfaces was probably occurring during the extended storage in the lab. Assuming that much of the initial $\mathrm{AE}$ was caused by oxidation effects, then the decreasing $\mathrm{AE}$ rate 


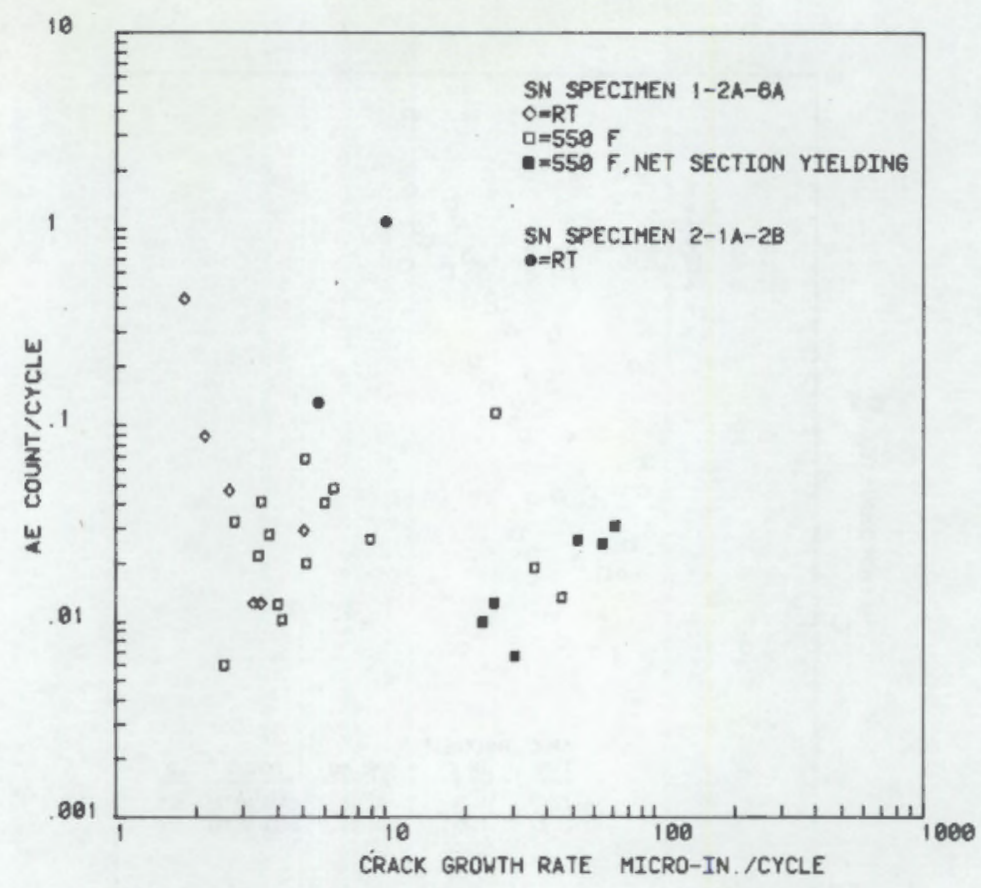

FIGURE 4. AE Rate Versus Fatigue Crack Growth Rate for SN Type Specimens $(R=0.1)$

with increasing crack growth is attributed to movement of the crack front away from the oxidized fracture surfaces. For more evidence of this effect, see the Characterizations Section.

To compare the effect of defect geometry upon the AE rate, a composite plot of all FCG data is shown in Figure 5. The composite plot was constructed from the data in Figures 2 to 4 . Each defect type is distinguished by a seperate color as noted in Figure 5 . The results indicate no significant differences between the various defect geometries. This contrasts with the fracture test results which do tend to depend upon the defect geometry.

\section{FRACTURE}

Fracture tests on laboratory specimens and 6-in-thick, intermediatescale, HSST pressure vessels, ${ }^{(2,3)}$ have also been monitored using AE. The fracture test conditions are summarized in Table 2. The laboratory test results are plotted in Figures 6 to 13 and the vessel test data are shown in Figures 14 and 15 . The AE-fracture test results for all test conditions show that $A E$ response increases with flaw severity. 


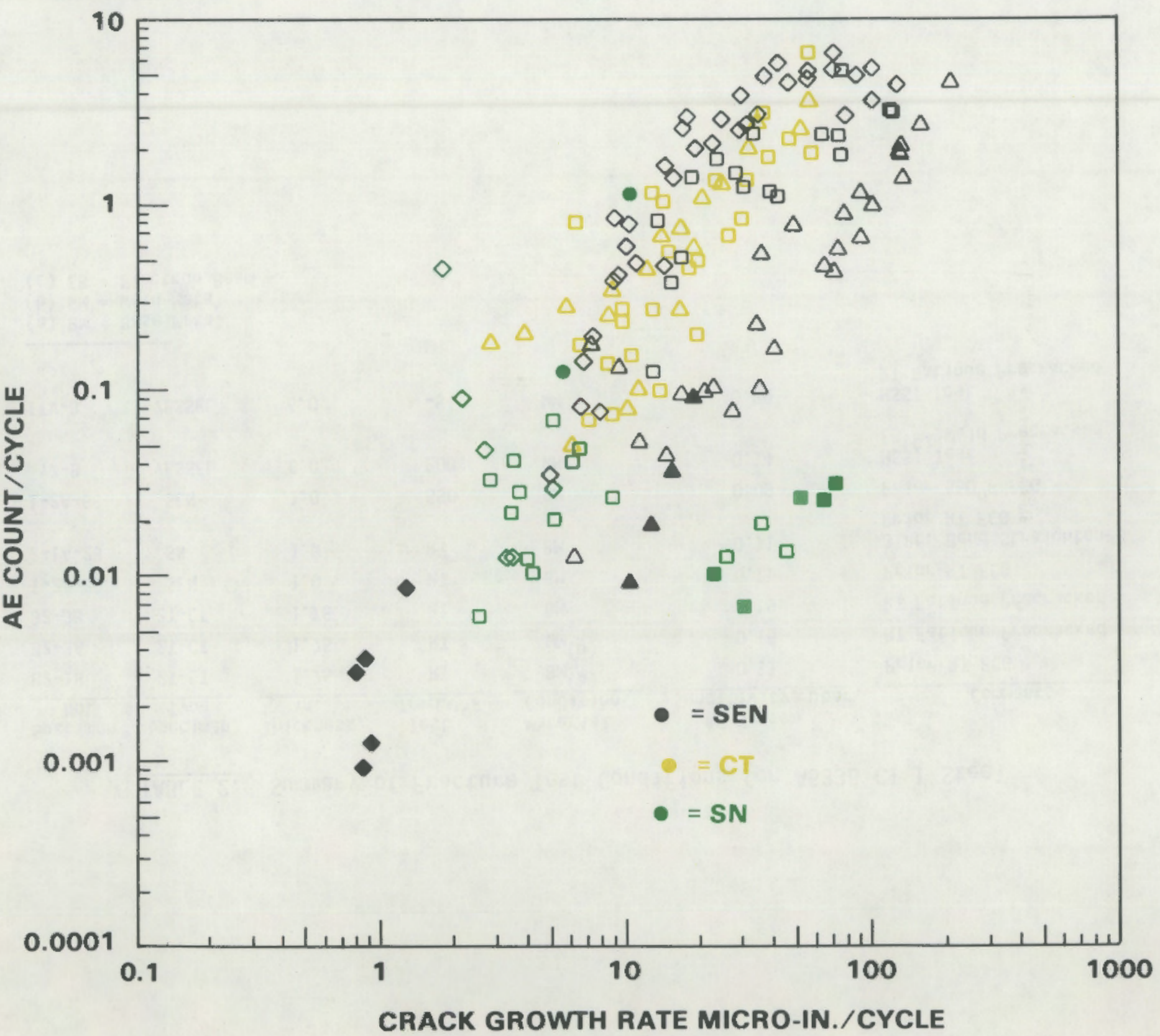

FIGURE 5. AE Rate Versus Fatigue Crack Growth Rate for SEN, 2T-CT, and SN Type Specimens 
TABLE 2. Summary of Fracture Test Conditions for A533B CI 1 Steel

\begin{tabular}{|c|c|c|c|c|c|c|}
\hline $\begin{array}{c}\text { Specimen } \\
\text { No. } \\
\end{array}$ & $\begin{array}{l}\text { Specimen } \\
\text { Type } \\
\end{array}$ & $\begin{array}{l}\text { Thickness, } \\
\text { in. } \\
\end{array}$ & $\begin{array}{l}\text { Test } \\
\text { Temp, }{ }^{\circ} \mathrm{F} \\
\end{array}$ & $\begin{array}{l}\text { Material } \\
\text { Condition }\end{array}$ & $\begin{array}{c}\text { AE System } \\
\text { Sensitivity, } \mu \text { bar }\end{array}$ & Comments \\
\hline$B 2-1 B$ & $2 \mathrm{~T}-\mathrm{CT}$ & 1.75 & RT & $B M(a)$ & 0.11 & Prior RT FCG \\
\hline$B 2-3 A$ & 2T-CT & 1.75 & RT & WM $(b)$ & 0.16 & RT Fatigue Precracked \\
\hline$B 2-3 B$ & $2 \mathrm{~T}-\mathrm{CT}$ & 1.75 & RT & $B M$ & 0.19 & RT Fatigue Precracked \\
\hline $1-2 A-2 B$ & SEN & 1.0 & RT & $B M$ & 0.11 & Prior RT FCG \\
\hline $2-1 A-2 B$ & SN & 1.0 & RT & BM & 0.11 & $\begin{array}{l}3 \text { Pt. Bend Straightened } \\
\text { Prior RT FCG }\end{array}$ \\
\hline $1-2 A-6 B$ & SEN & 1.0 & 550 & BM & 0.09 & Prior $550^{\circ} \mathrm{F} \mathrm{FCG}$ \\
\hline V7-B & VESSEL & 6.0 & 200 & WM & 0.14 & $\begin{array}{l}\text { HSST Test } \\
\text { EB } \\
\text { (C) }{ }^{\text {Teld }} \text { Precracked }\end{array}$ \\
\hline ITV -8 & VESSEL & 6.0 & -5 & WM & 0.20 & $\begin{array}{l}\text { HSST Test } \\
\text { RT Fatigue Precracked }\end{array}$ \\
\hline
\end{tabular}

\footnotetext{
(a) $B M=$ Base Metal

(b) $W M=$ Weld Metal

(c) $\mathrm{EB}=$ Electron Beam
} 


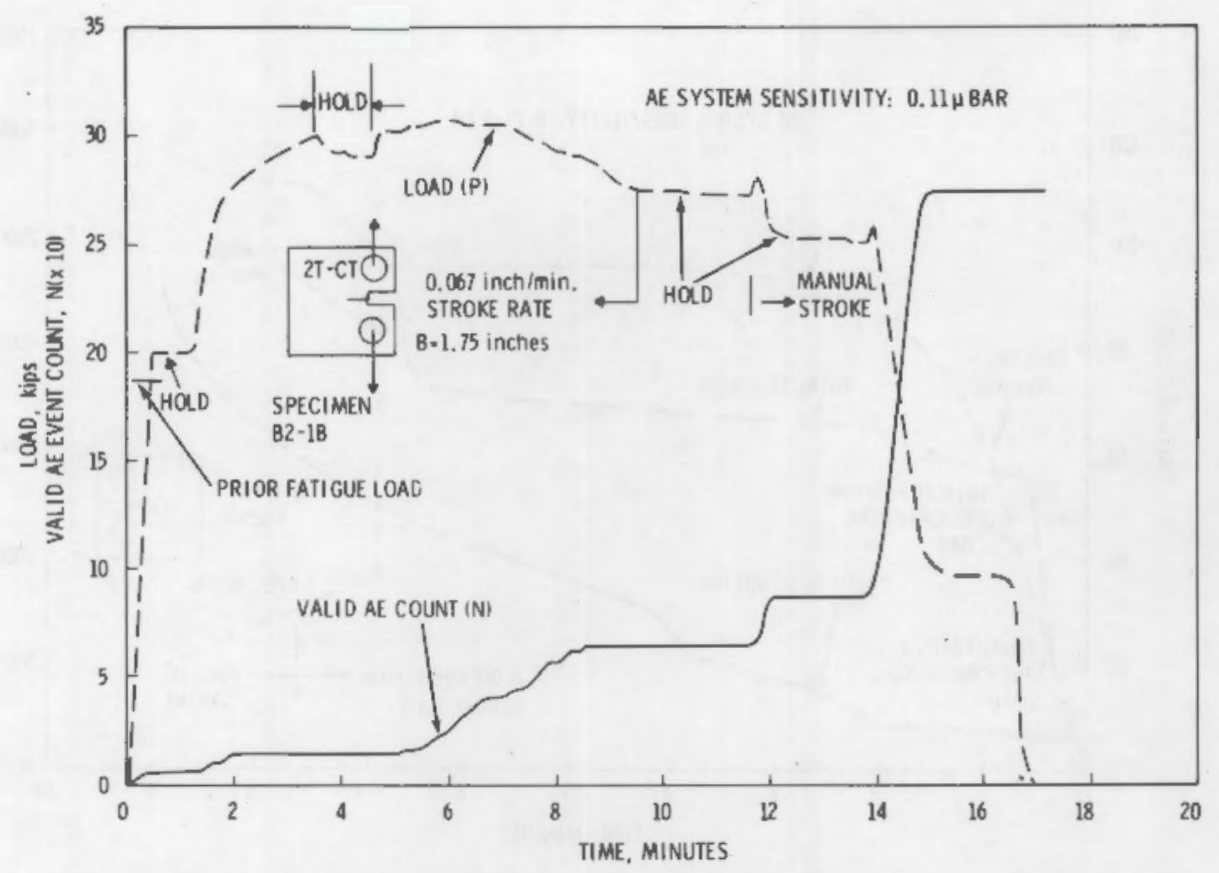

FIGURE 6. Fracture Test B2-1B Data--Base Metal
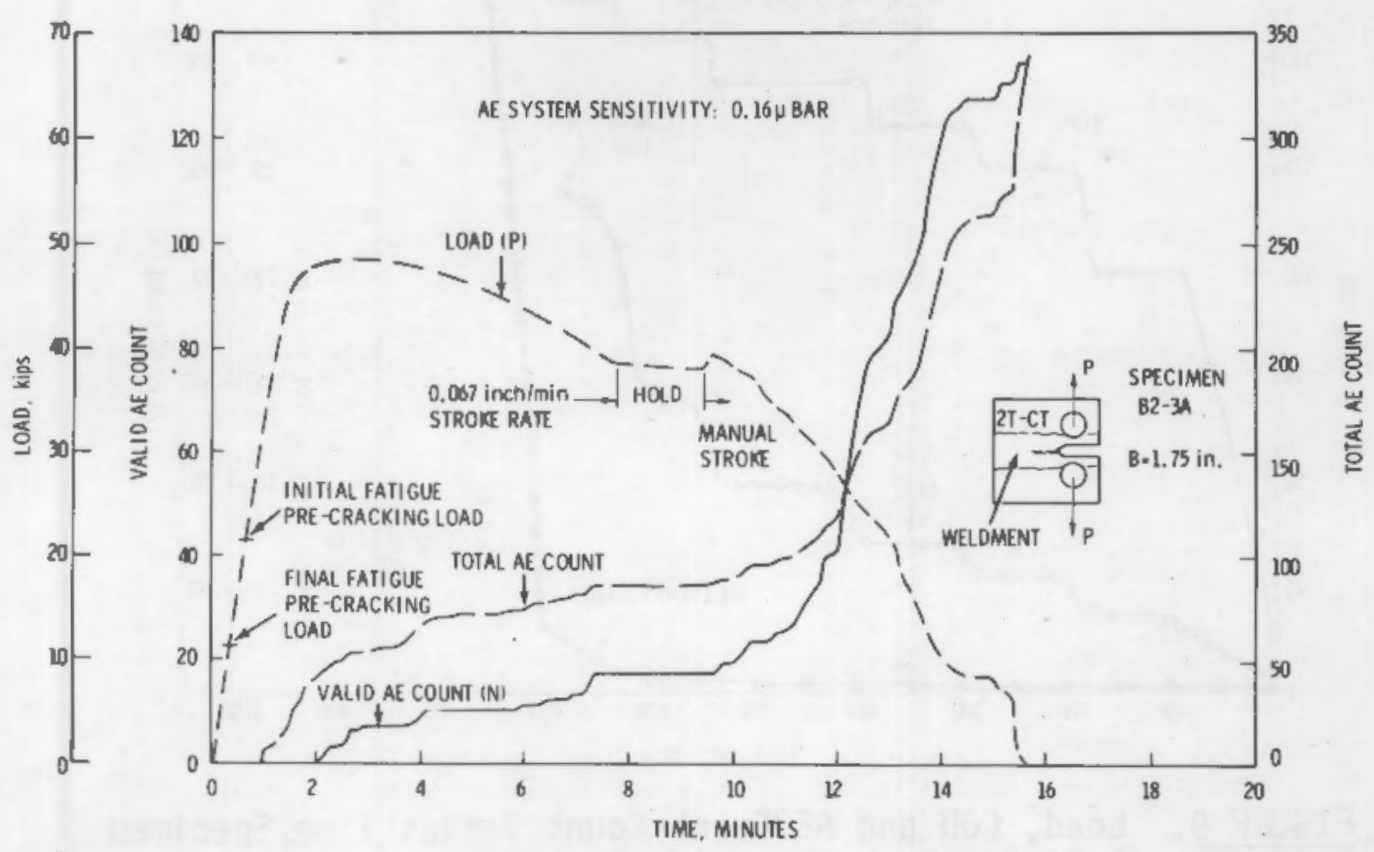

FIGURE 7. Fracture Test B2-3A Data--Weld Metal 


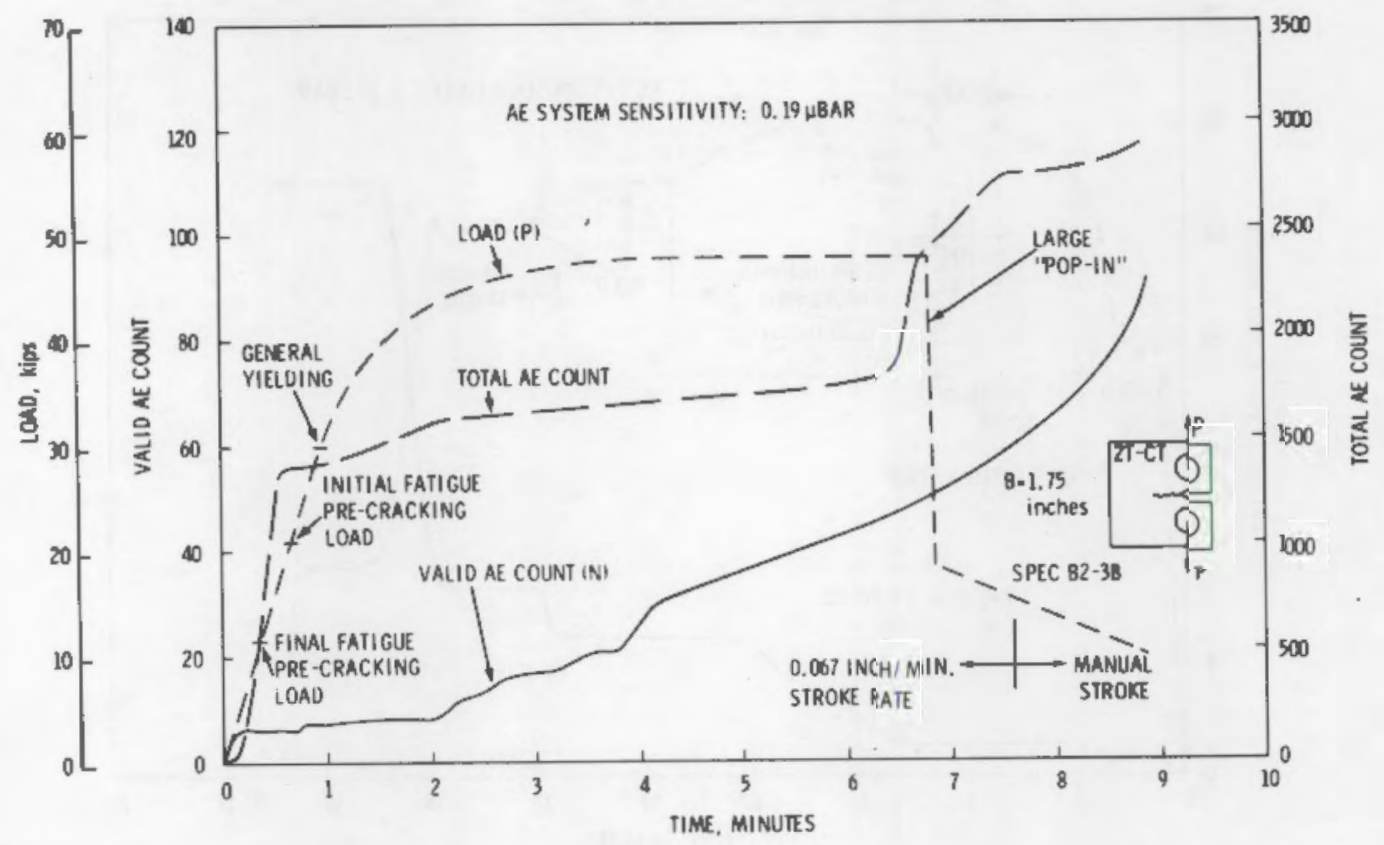

FIGURE 8. Fracture Test B2-3B Data--Base Metal

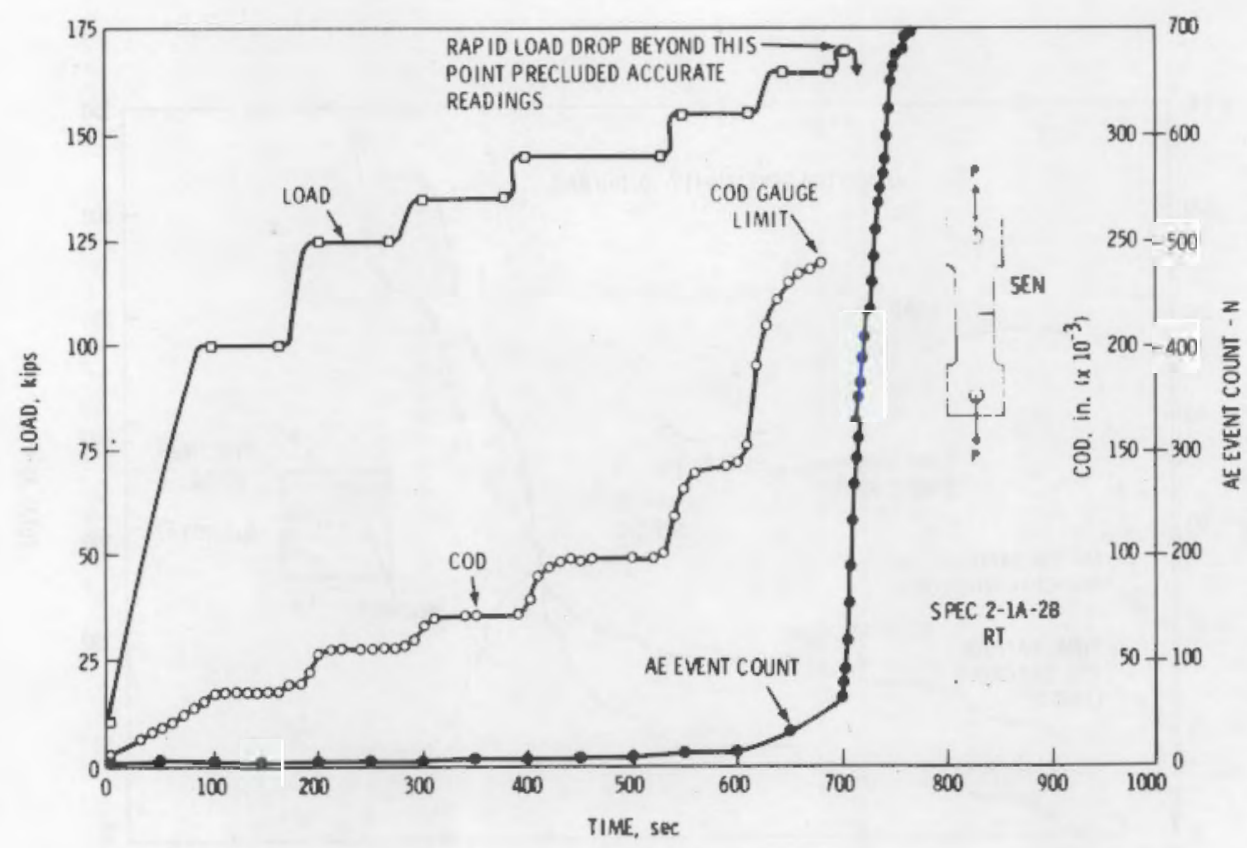

FIGURE 9. Load, COD and AE Event Count Versus Time, Specimen 1-2A-2B, Room Temperature. (Maximum final fatigue pre-crack load was $15 \mathrm{kip}$ ) 


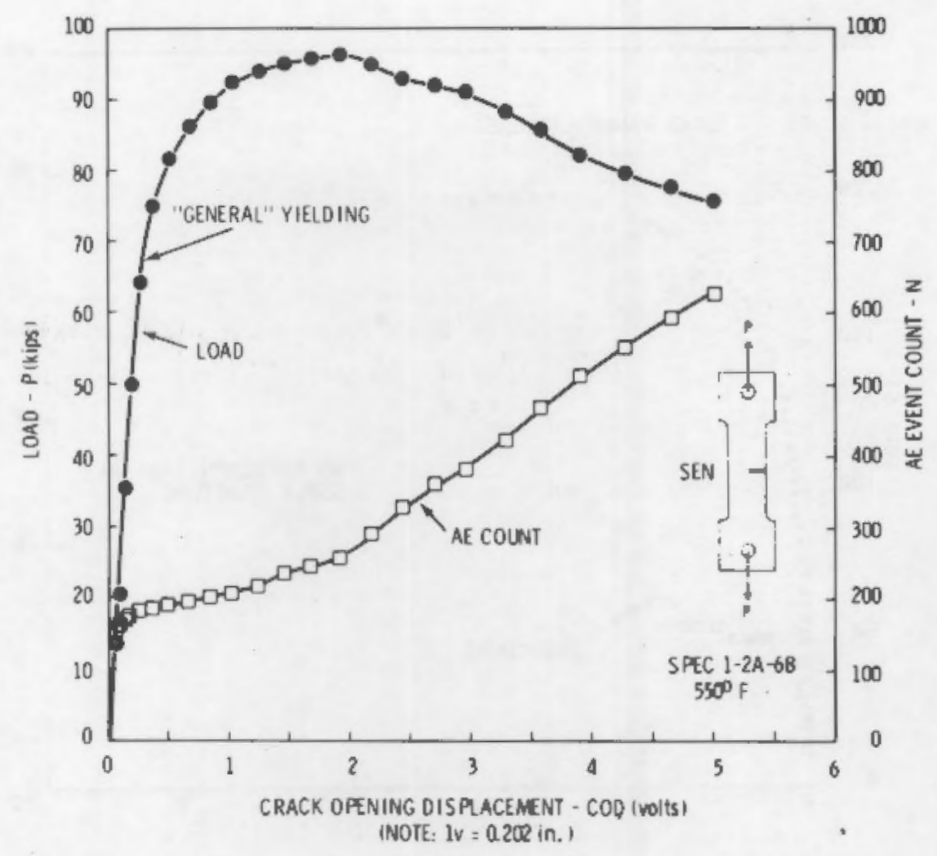

FIGURE 10. Load and AE Event Count Versus COD, SEN Specimen 1-2A-6B, 5500F

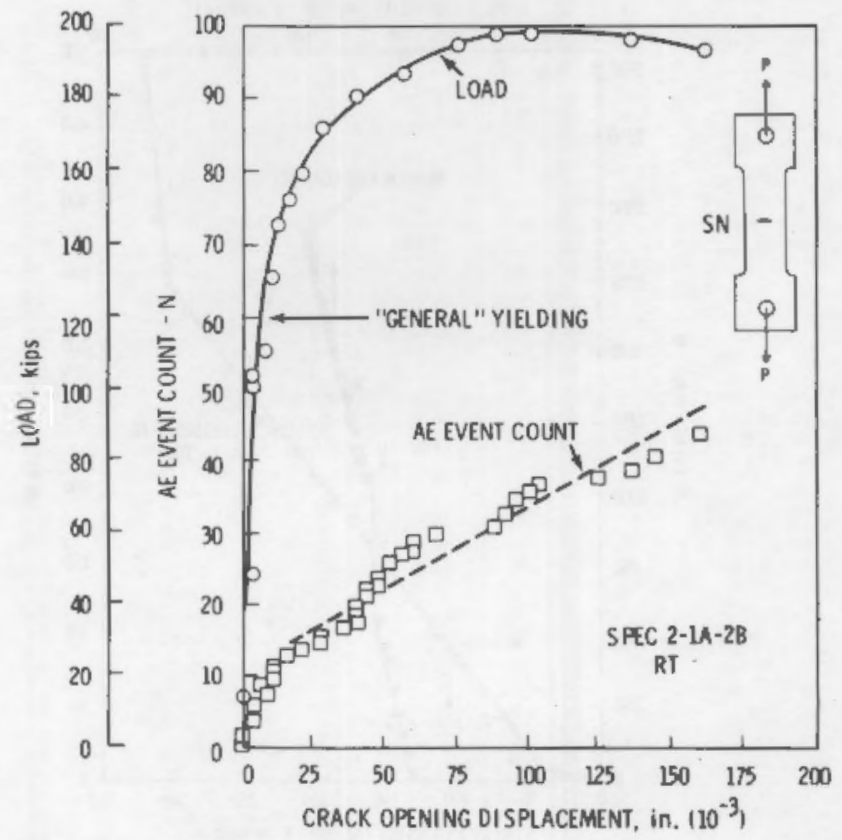

FIGURE 11. Load and AE Event Count Versus COD, SN Specimen 2-1A-2B, Room Temperature 


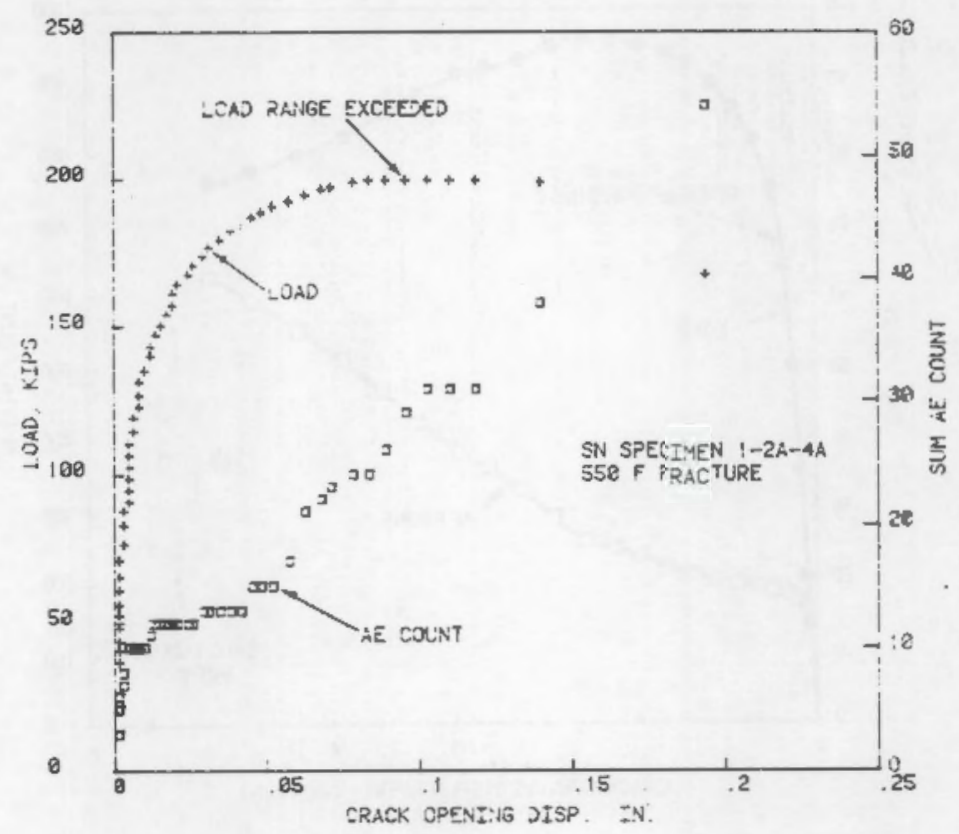

FIGURE 12. Load and AE Event Count Versus COD, SN Specimen $1-2 A-4 A, 550 \circ$

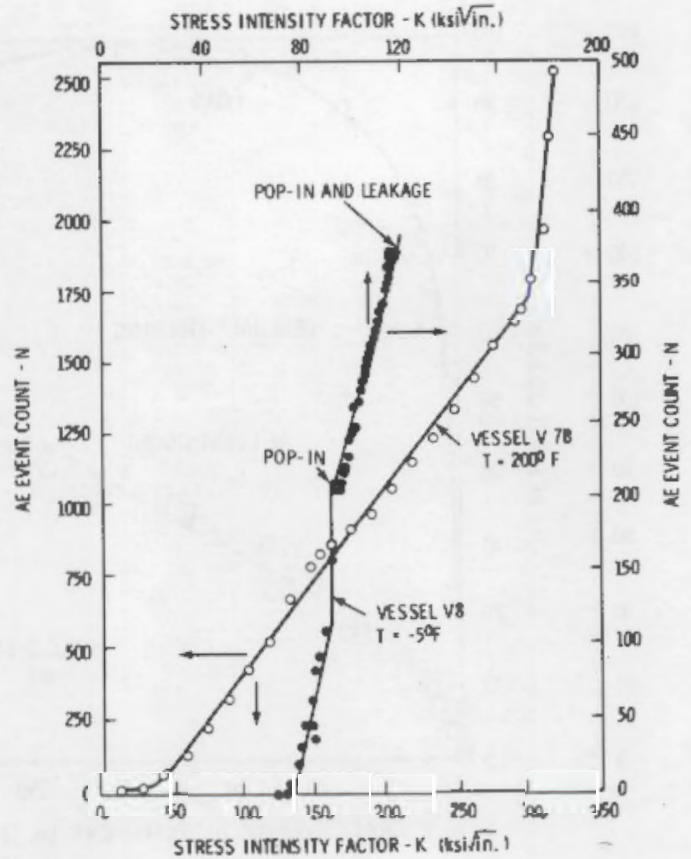

FIGURE 13. Summation AE Versus K for Vessel V7-B (200\%) and $\mathrm{V} 8$ ( $-5^{\circ \mathrm{OF})}$ 

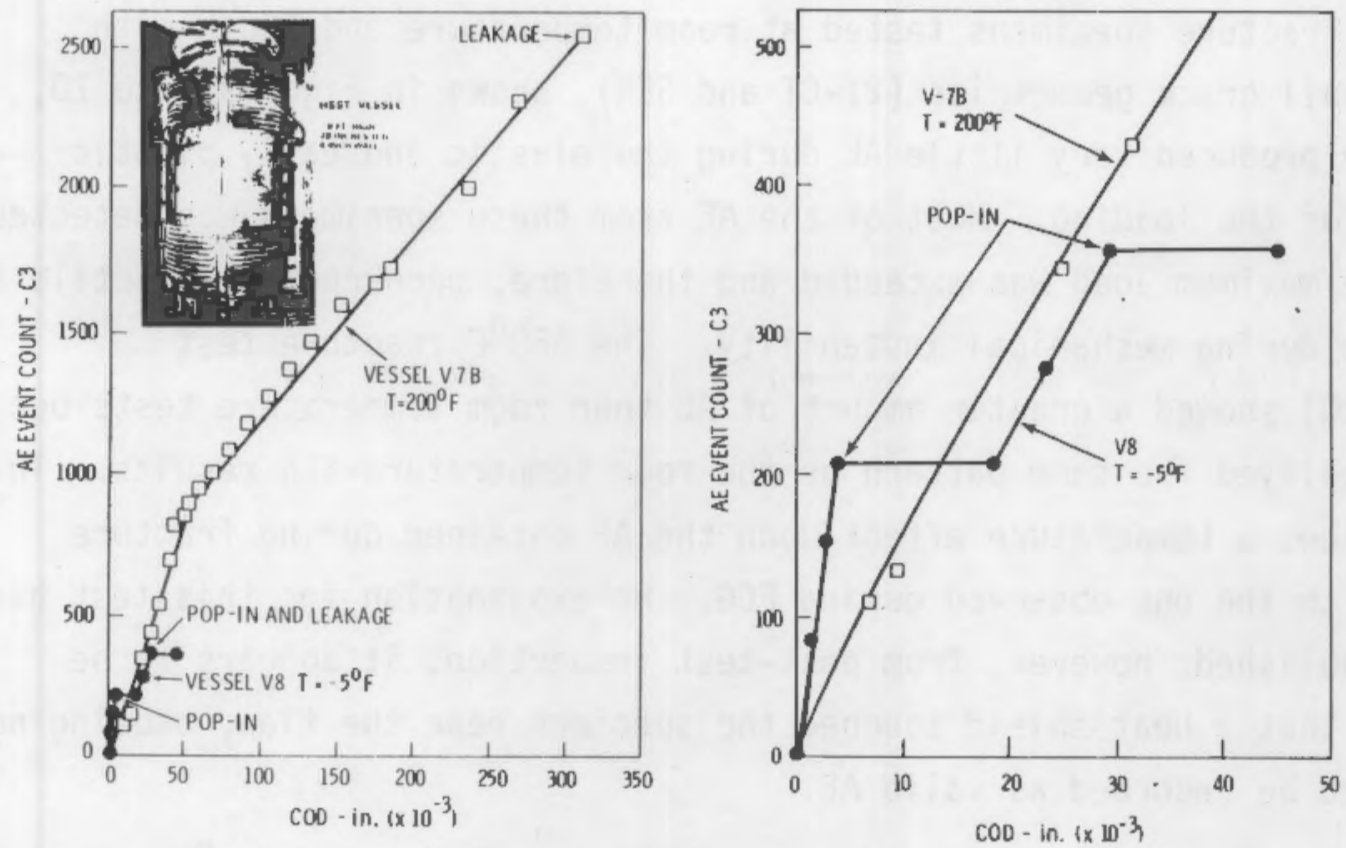

FIGURE 14. Summation AE Versus COD for Vessel V7-B (200\% F) and $V 8\left(-5^{\circ} \mathrm{F}\right)$

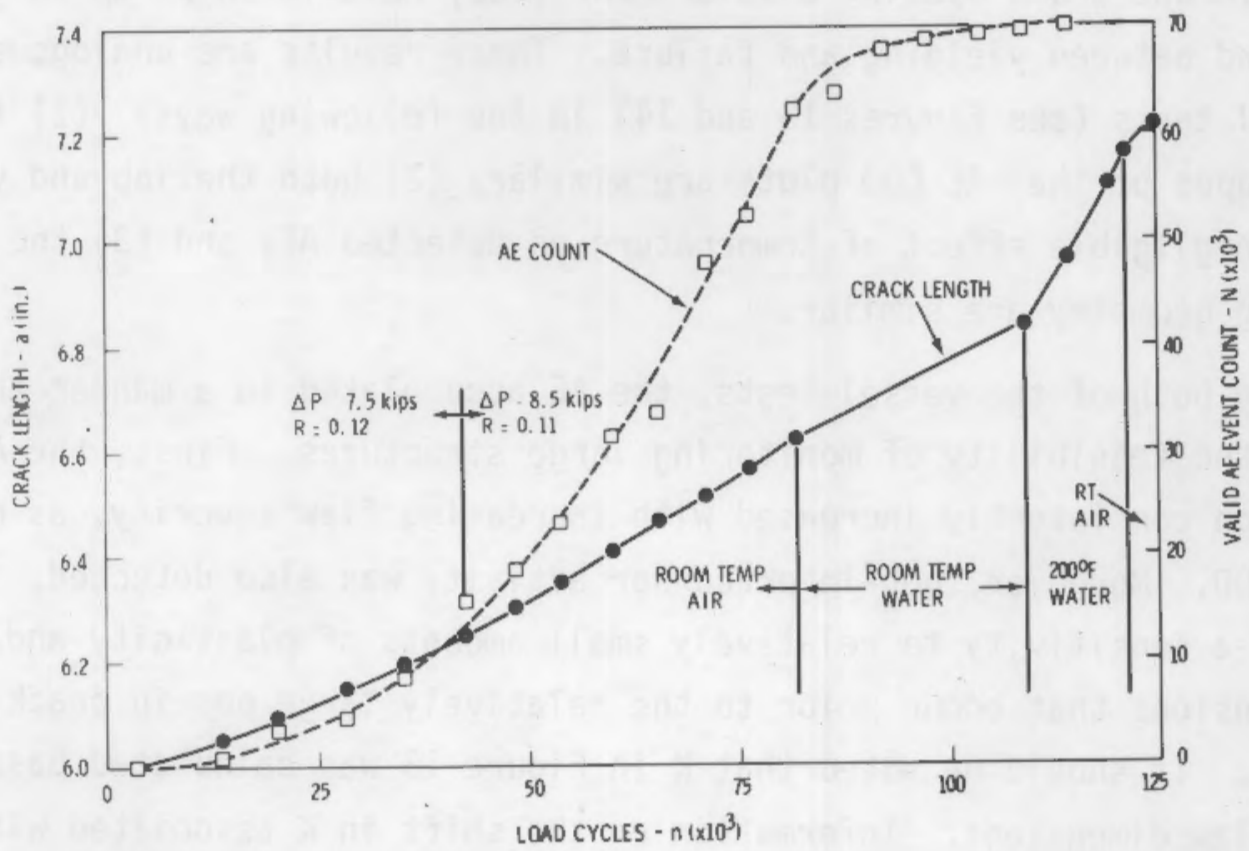

FIGURE 15. Crack Growth and AE Versus Load Cycles for Fatigue Crack Growth in Air and Water 
The fracture specimens tested at room temperature and $550^{\circ} \mathrm{F}$ with through-wall crack geometries (2T-CT and SEN), shown in Figures 6 to 10 , generally produced very little AE during the elastic and early plastic portions of the loading. Most of the AE from these specimens was detected after the maximum load was exceeded and therefore, occurred from ductile crack extension during mechanical instability. The $550^{\circ} \mathrm{F}$ fracture test (Figure 10) showed a greater amount of AE than room temperature tests but still displayed the same pattern as the room temperature-SEN results. This result shows a temperature effect upon the $A E$ obtained during fracture opposite to the one observed during FCG. No explanation for this test has been established; however, from post-test inspection, it appears to be possible that a heat shield touched the specimen near the flaw, causing noise signals to be recorded as valid AE.

Two fracture tests (one at room temperature and one at $550^{\circ} \mathrm{F}$ ) were conducted on specimens with part-through wall SN configurations, which yielded results different from the through-wall data (see Figures 11 and 12). In these instances, AE was detected both before and after general yielding, with linear AE versus crack opening displacement (COD) relationships up to general yielding and between yielding and failure. These results are analogous to the HSST vessel tests (see Figures 13 and 14) in the following ways: (1) the general shapes of the AE-COD plots are similar; (2) both the lab and vessel data show negligible effect of temperature on detected AE; and (3) the crack and loading geometry are similar.

During both of the vessel tests, the $\mathrm{AE}$ accumulated in a manner that indicated the feasibility of monitoring large structures. First, the AE accumulation consistently increased with increasing flaw severity, as measured by $\mathrm{K}$ and $\mathrm{COD}$. Moreover, pop-in precursor activity was also detected, indicating a sensitivity to relatively small amounts of plasticity and/or crack extensions that occur prior to the relatively large pop-in crack extensions. It should be noted that $K$ in Figure 13 was calculated based on original flaw dimensions. Information on the shift in $K$ associated with the pop-in in vessel 18 is not yet available. During the most dynamic part of the pop-ins (including leakage) where the signal density was very high (as observed 
on an oscilloscope), the AE system locked out. This was due to a design feature to avoid multiple counts from one signal. A different design commonly used in field monitoring systems would have shown a very sharp increase in response to the high-density data, thus providing a bench mark to signify occurrence of a pop-in.

The AE-COD curves for both vessel tests (Figure 14) remained linear to failure (leakage) even though, in the case of the $200^{\circ} \mathrm{F}$ test, significant crack extension was occurring near the end of the test, as suggested by the AE-K curve (Figure 13). The fact that the COD seems to correlate more effectively than $\mathrm{K}$ with $\mathrm{AE}$ during fracture indicates that flaw damage models based strictly on linear elastic fracture mechanics may not adequately model the data. However, the laboratory SN and HSST results indicate AE response to be a feasible method for monitoring the flaw severity of part-through cracks in large structures.

\section{CHARACTERIZATIONS}

The analysis of measured AE signal parameters from various sources-energy, peak time, amplitude, first half-cycle polarity--has not shown any consistent characterization. New approaches to AE characterization are planned as discussed under recommendations for future work.

A double cantilever beam (OCB) specimen was used to investigate the effects of water on AE from FCG. The results (Figure 15) showed a decrease in AE (particularly high-amplitude signals) upon immersion of the specimen in water. The decrease in detected AE could be due to surface wave damping by water, dissipation of body wave energy through the specimen-to-water interface, a decrease in crack-face noise, or a combination of these. In a different program, tests involving water did not show significant effect. A resolution of these differences is being investigated.

The specimen used for the water-effect tests was subsequently used to investigate the characteristics of oxide in a fatigue crack. An oxide was formed on the fatigue crack fracture surfaces by loading the specimen to open the crack, inserting a wedge to keep the crack open, and then immersing the 
specimen in distilled water for about six weeks. AE was obtained during unload following wedge removal (Figure 16) and subsequent fatigue cycling (Figure 17), which produced approximately 1/4 in. of crack growth. When compared to AE from FCG in the same specimen prior to oxidation, the "oxide data" showed that the initial AE data rate in the absence of FCG was high relative to $A E-F C G$ data obtained from unoxidized specimens. Once the fatigue crack front moved away from the oxidized fracture faces, the $A E$ rate returned to levels similar to that obtained for FCG in air prior to oxidation.

A slag inclusion test specimen and an associated slag-free control specimen were fabricated from weld material provided from the GATX AE-weld monitor program. Both specimens were tested under cyclic loading with similar stress levels. The results (Figure 18) show that the average $A E / c y c l e$ for the slag inclusion specimen was about 4-1/2 times that for the control specimen at the higher stress levels ( 3200 to $16,000 \mathrm{psi})$. The results are inconclusive, however, because:

- The AE signal parameters measured did not show any unique features or consistent pattern differences between the two specimens.

- The apparent slag inclusion was very small (approximately 0.015 in. diameter).

- An uncertainty exists as to how much of the flaw was slag inclusion versus void.

- Incomplete fusion along the loading axis of the slag inclusion specimen definitely occurred and may have had an effect on the results.

\section{HIGH-TEMPERATURE AE SENSOR}

The objective of high-temperature sensor testing is to test the feasibility of using available high-temperature $A E$ sensors for continuous monitoring of reactor pressure boundaries. Three high-temperature sensors have been screened by laboratory testing at $550^{\circ} \mathrm{F}\left(288^{\circ} \mathrm{C}\right)$ with the expectation that development of a new high-temperature sensor concept could be avoided at least for the near future. The results to date are encouraging. 


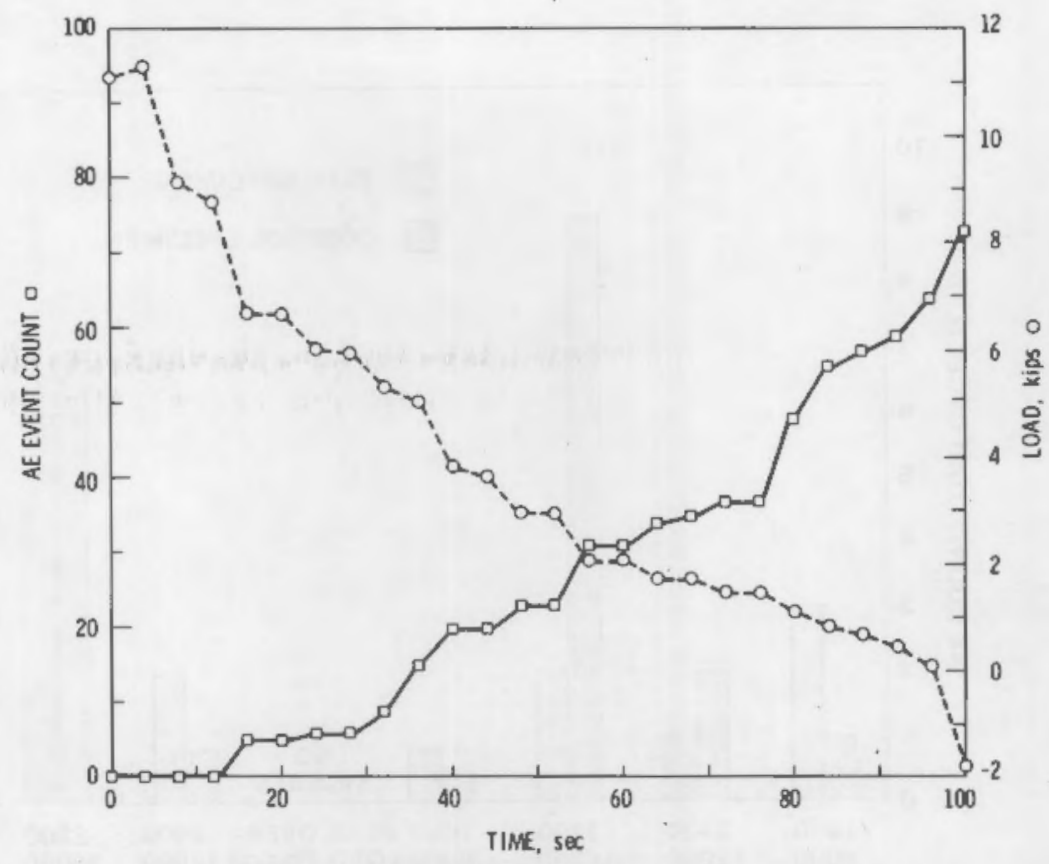

FIGURE 16. AE Count and Load Data Versus Time for DCB Specimen 1-2A-5A-4-Following a Six-Week Exposure in Room Temperature Distilled Water

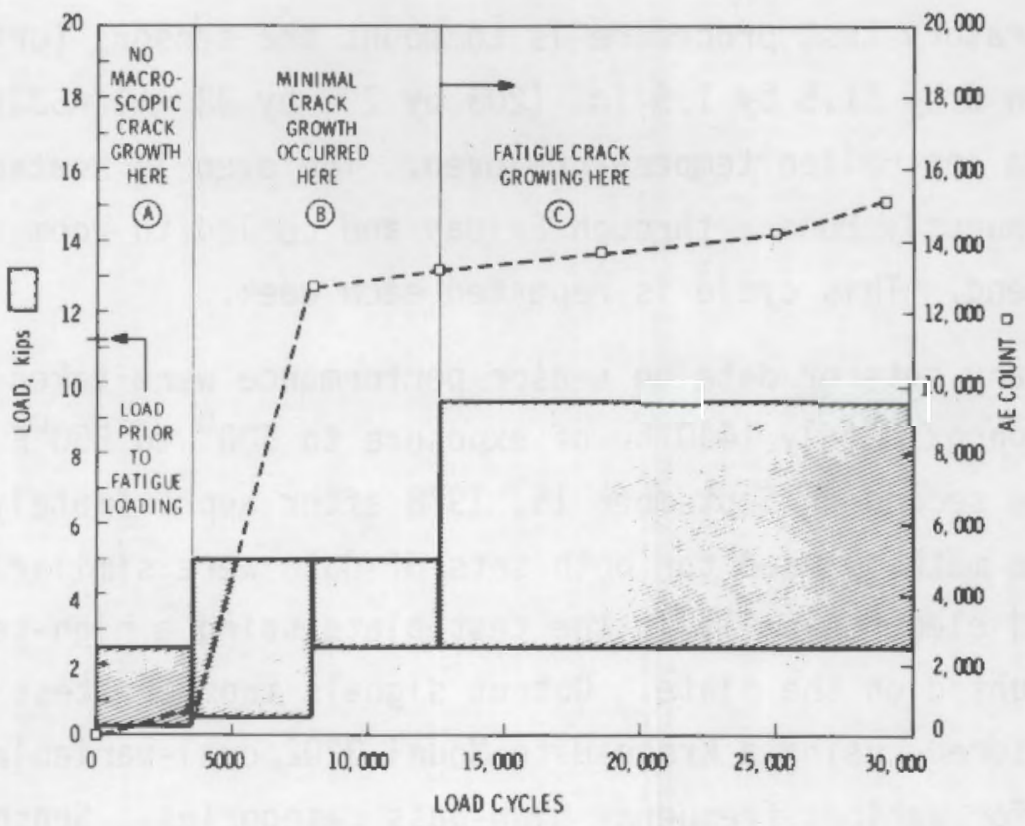

FIGURE 17. AE Count and Loading Range Data Versus Total Load Cycles for DCB Specimen 1-2A-5A-4 Following a Six-Week Exposure in Room Temperature Distilled Water 


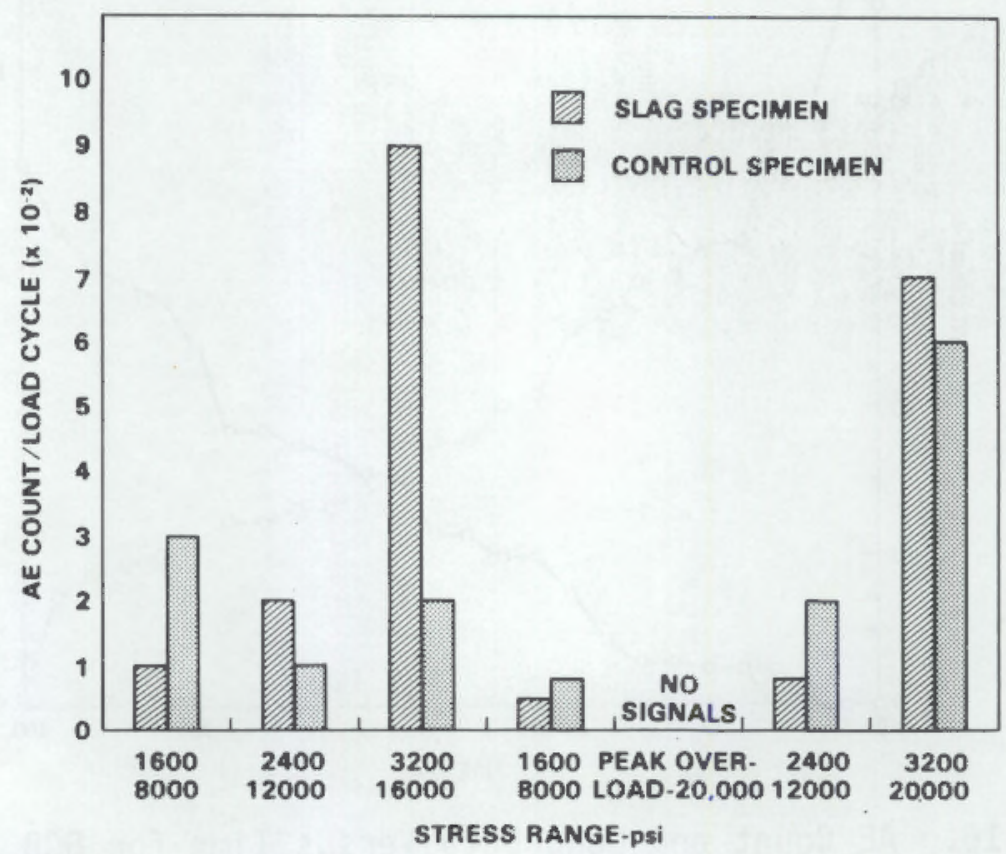

FIGURE 18. High Temperature Sensor Response to a Constant Pulse Input to Test Plate Measured at $550^{\circ} \mathrm{F}$

The laboratory test procedure is to mount the sensors (dry pressure coupled) on an 8 by 11.5 by $1.5 \mathrm{in.}$ (203 by 292 by $38 \mathrm{~mm}$ ) A533B steel plate installed in a controlled temperature oven. The oven is heated to $550^{\circ} \mathrm{F}$ $\left(288^{\circ} \mathrm{C}\right)$ continuously Monday through Friday and cooled to room temperature over the weekend. This cycle is repeated each week.

Two primary sets of data on sensor performance were taken--one on June 1 , 1978, after approximately $1440 \mathrm{hr}$ of exposure to $500^{\circ}$ to $550^{\circ} \mathrm{F}$ (260 to $288^{\circ} \mathrm{C}$ ) and the second on September 15, 1978 after approximately $2830 \mathrm{hr}$ exposure. The methods used for both sets of data were similar. Pulse signals were generated electronically in the test plate using a high-temperature transducer mounted on the plate. Output signals from the test sensors were frequency filtered, using a Krohn-Hite Model 3202 dual-variable filter to produce data for various frequency high-pass categories. Sensor response results are shown in Figures 19 and 20 . The June 1 measurements were made at room temperature to permit including a laboratory sensor for comparison. The September 15 measurements were made at $550^{\circ} \mathrm{F}\left(288^{\circ} \mathrm{C}\right)$. 


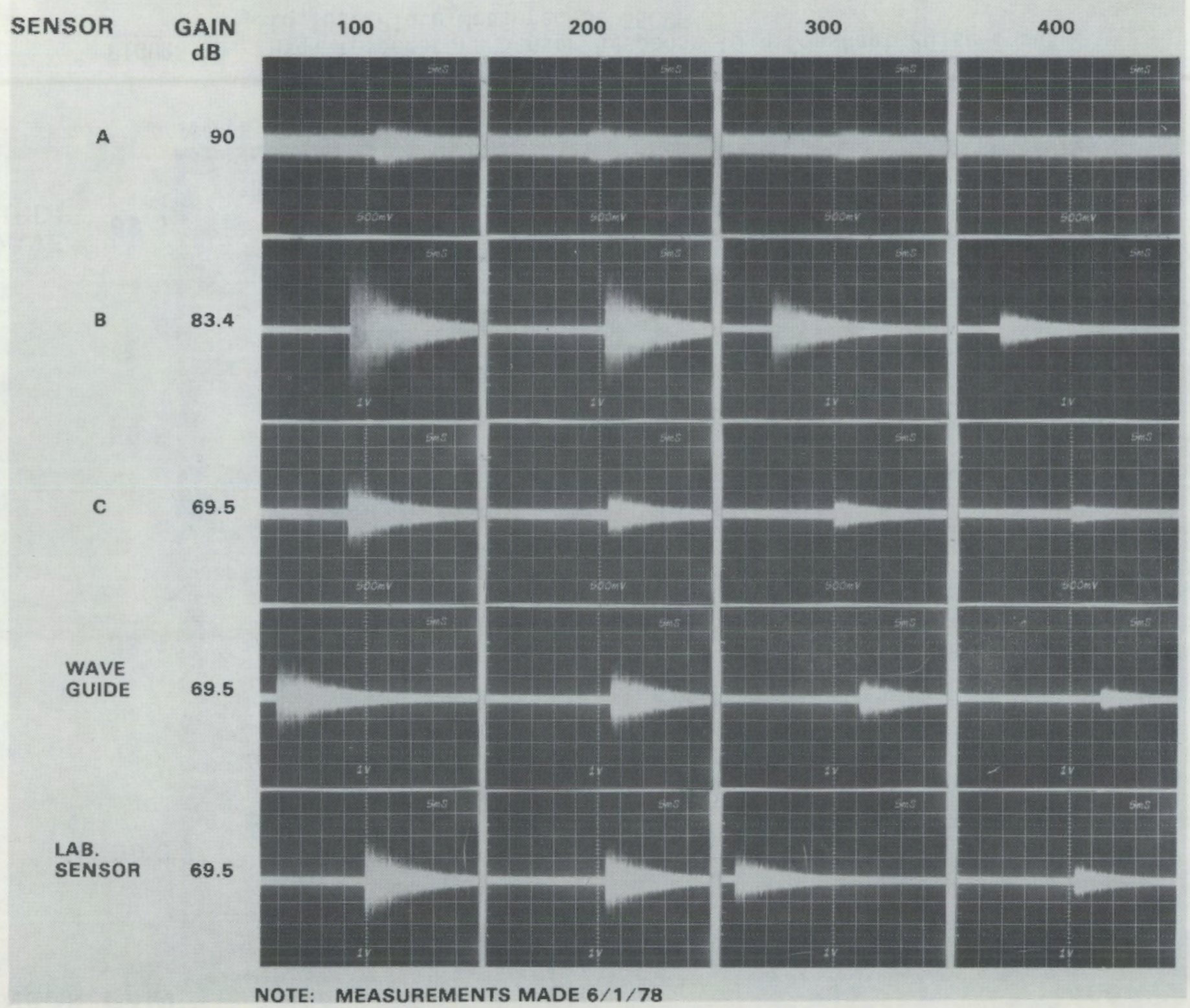

FIGURE 19. High Temperature Sensor Response to a Constant Pulse Input to Test Plate Measured at Room Temperature 


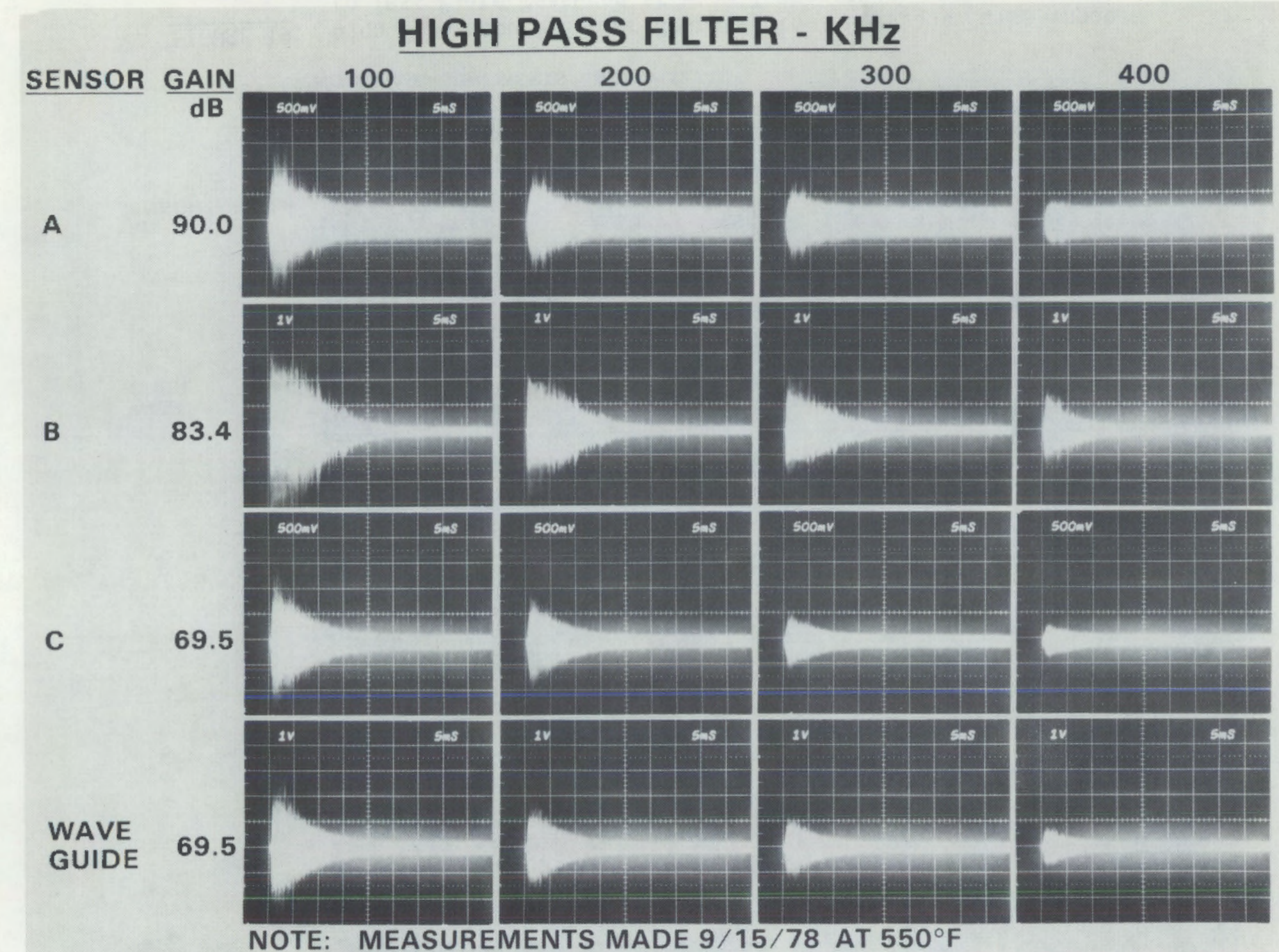

FIGURE 20. High Temperature Sensor Response to a Constant Pulse Input to Test Plate Measured at $550^{\circ} \mathrm{F}$ 
One aspect of the data which was evaluated was the response versus increasing lower frequency limit. It appears that continuous monitoring of a vessel during operation would likely need to be done with a lower frequency limit of about $400 \mathrm{kHz}$ to avoid hydraulic noise interference.

Another consideration examined was $S / N$ ratio. $S / N$ ratio is significant to any $A E$ monitor system that utilizes a threshold limit for signal detection (nearly all current systems do). Table 3 gives the results of S/N ratio determination. observations from these results are:

- The input signal in the 09/15/78 test may have been slightly stronger than in the $06 / 01 / 78$ test; however, the $09 / 15 / 78$ test was run at $550^{\circ} \mathrm{F}$ which may also contribute the stronger response in that test.

- Sensor 8 is very promising. It retains about $35 \%$ of its broadband sensitivity at the $400 \mathrm{kHz}$ condition and the $S / N$ ratio at $400 \mathrm{kHz}$ is equal to that of the laboratory sensor. We consider this to be important to a field application consideration. An $S / N$ ratio of less than 2 to 3 would be marginal.

- The metal wave guide represented in these tests is a concept long recognized as one method of $A E$ monitoring a high-temperature surface. It has some disadvantage over a surface-mounted sensor (such as Sensor B). The wave guide will generally influence the character of the signal received out of the piezoelectric crystal at its outer end. To effectively protect the piezoelectric crystal from overheating, the wave guides are often several feet long, which makes them subject to physical damage. The wave guide is, however, a demonstrated method of detecting $A E$ events from a high-temperature surface.

- Two sensor concepts--Sensor 8 and the metal wave guide--appear at this time to present viable methods of detecting $A E$ on a reactor pressure vessel. The final test process will consist of exposing them to an actual reactor environment (temperature plus nuclear radiation). Arrangements for this are in progress. 
TABLE 3. Signal-to-Noise Ratio for High-Temperature Sensors

$$
\text { 06/01/78 }
$$

\begin{tabular}{|c|c|c|c|c|c|}
\hline \multirow{2}{*}{ Sensor } & \multirow[b]{2}{*}{ Gain, dB } & \multicolumn{4}{|c|}{ High Pass Filter, $\mathrm{kHz}$} \\
\hline & & $\underline{100}$ & 200 & 300 & 400 \\
\hline A & 90.0 & 2 & 1.4 & 1.1 & -- \\
\hline B & 83.4 & 20 & 15 & 11 & 6 \\
\hline c & 69.5 & 7 & 5.6 & 4 & 1.6 \\
\hline Wave Guide & 69.5 & 11 & 9 & 6 & 2.5 \\
\hline Lab Sensor & 69.5 & 12 & 10 & 7.5 & 6 \\
\hline
\end{tabular}

\begin{tabular}{|c|c|c|c|c|c|}
\hline \multirow[b]{2}{*}{ Sensor } & \multicolumn{3}{|c|}{$09 / 15 / 78$} & & \\
\hline & Gain, dB & $\underline{100}$ & 200 & 300 & $\underline{400}$ \\
\hline A & 90.0 & 4.7 & 3.2 & 2.7 & 1.3 \\
\hline B & 83.4 & 17.5 & 14.0 & 11.5 & 7.5 \\
\hline C & 69.5 & 10.0 & 6.7 & 4.0 & 2.3 \\
\hline Wave Guide & 69.5 & 12.0 & 7.2 & 5.2 & 3.2 \\
\hline
\end{tabular}




\section{AE/FLAW MODEL DEVELOPMENT}

\section{EMPIRICAL MODELS}

Two empirical models have been used to describe fatigue crack growth data. The first model uses a power-law expression to relate the rate of change of $A E$ variables to $F C G$ parameters such as the stress intensity factor range $(\Delta K)$ and the crack growth rate $(\mathrm{da} / \mathrm{dn})$. The expression is typically of the form:

$$
(d N / d n)=C_{0}(\Delta K)^{m}
$$

where $(\mathrm{dN} / \mathrm{dn})$ represents the number of AE counts per cycle. Conceptually, this approach allows a direct assessment of flaw severity by measuring the $A E$ count rate and temperature of the vessel (Figure 21). A knowledge of the flaw shape or the stress field in the vicinity of the suspected flaw should not be required. The influence of variables such as $R$ ratio, cycle rate, service loadings, material volume, and possible flaw geometry effect are yet to be defined. The work scheduled for $F Y_{-79}$ is aimed at investigating the effect of these variables. In addition, the data scatter associated with the current rate model is typically quite large. More extensive characterization of the AE signals with respect to mechanical parameters such as the $C O D$ and the position of the signal on the load waveform may improve the rate analys is method.

The second technique for correlating AE-FCG data is to plot the total accumulated $A E$ against either the stress intensity factor $(K)$ or the crack opening displacement (COD). In this instance, the summation AE versus $K$ or COD is usually linear and of the form:

$$
\Sigma N=B_{1} \quad K+B_{0}
$$

where $B_{1}$ and $B_{0}$ are constants. This approach is attractive because of the reduced data scatter and linear behavior (see Figure 22). It may, however, require an initial definition of flaw shape and stress field once the AE 


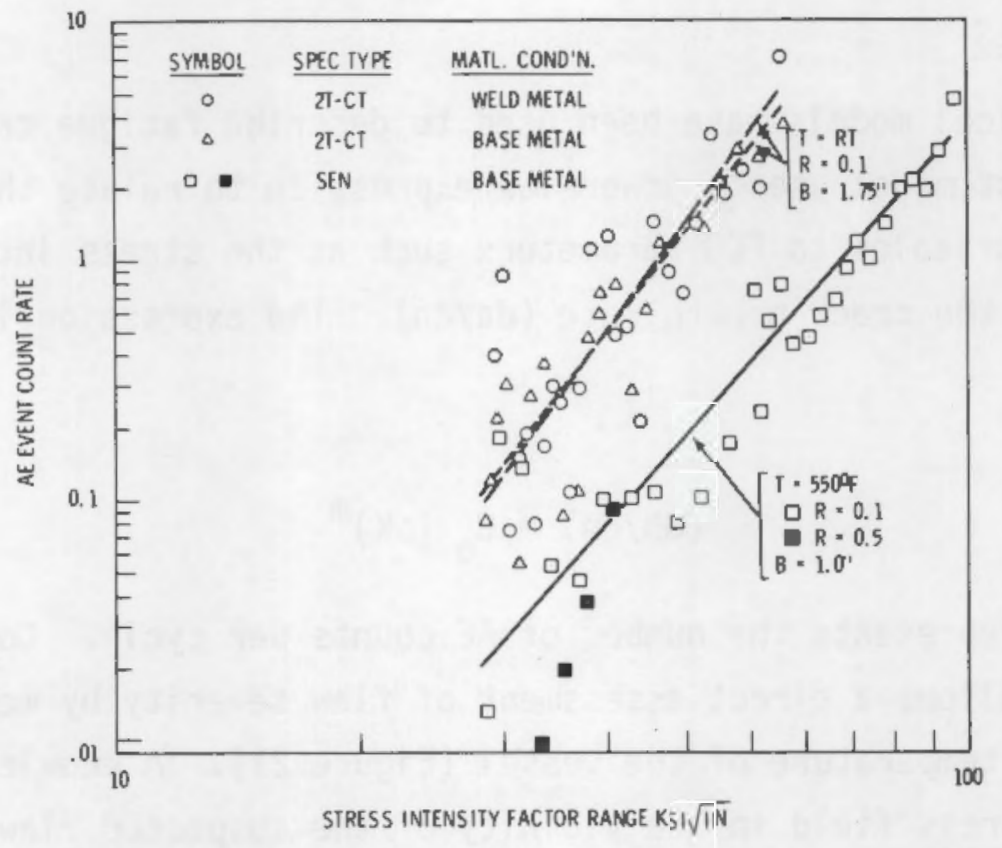

FIGURE 21. Composite AE Event Count Rate Versus $\triangle K$ Curves, Room Temperature and $550^{\circ} \mathrm{F}$

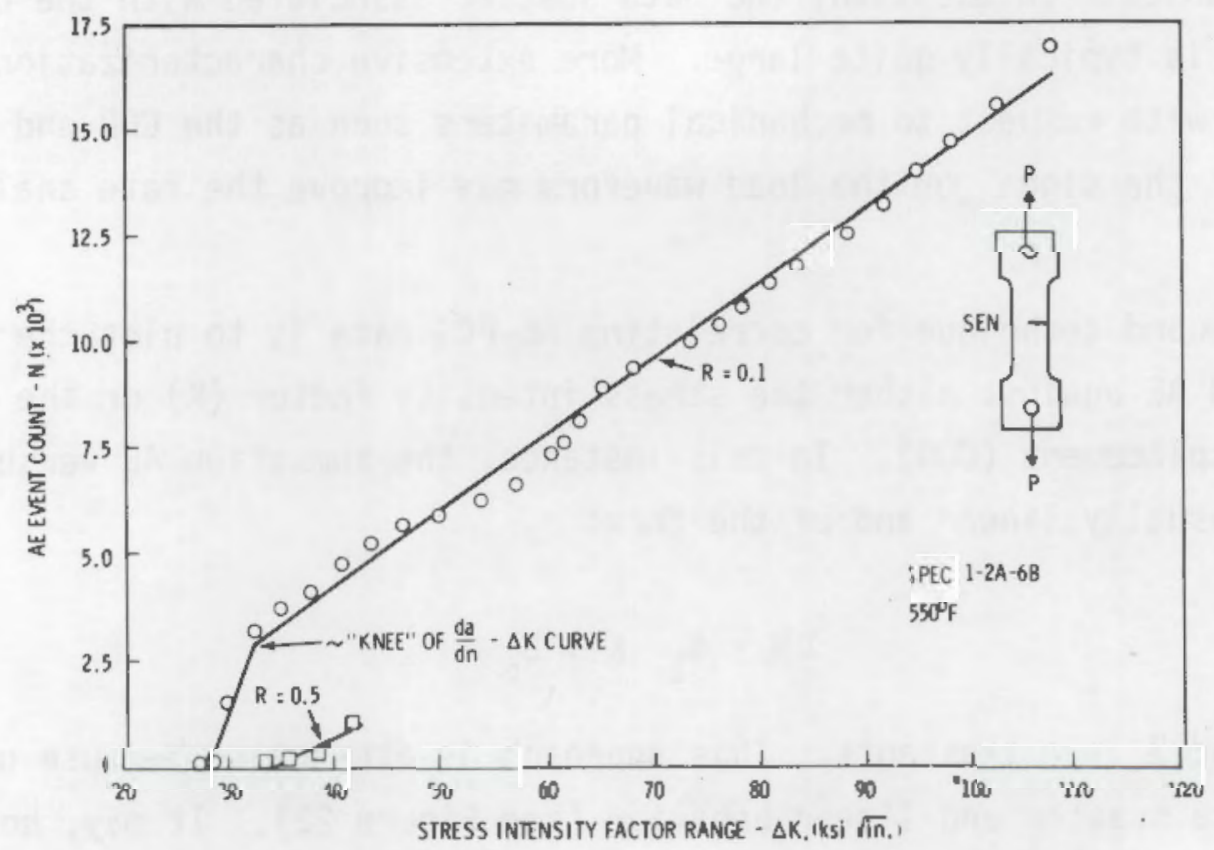

FIGURE 22. Surmation AE Event Count Versus $\Delta K$, Specimen $1-2 A-6 B, 550^{\circ} \mathrm{F}$ 
indicates a growing flaw. Again, as with the rate method, the effects of variables such as load cycle rate, R-ratio, simulated service loading, material volume, and temperature must be further defined.

The AE obtained from fracture tests run on intermediate scale pressure vessels has been correlated with both $K$ and COD. For two SN defect laboratory specimens, the results (Figures 11 and 12) have been correlated with COD only. No attempt was made to use $K$ in laboratory specimen calculations due to the early onset of net section yielding.

HSST pressure vessel tests (Figures 13 and 14) have produced excellent results between summation $A E$ and $C O D$ or $K$. In this case, the COD parameter was most effective at relating to the full range of the AE data. This result suggests that fracture mechanics variables which are sensitive to flaw plasticity may provide the best correlations with AE parameters.

\section{THEORETICAL MODELS}

Three theoretical models based upon linear elastic fracture mechanics were compared against the FCG results obtained from several different specimens. This section describes the models and compares the predicted results with the empirical results.

The first mode ${ }^{(4-7)}$ assumes that the number of $A E$ events, $N$, detected during FCG is proportional to the change in the crack tip plastic zone volume:

$$
d N=\alpha d V p
$$

where $\alpha$ is a material constant and $V p$ is the plastic zone volume. The term $V p$ is estimated from the following expression:

$$
V p=B \pi\left(r_{p}\right)^{2}=\frac{B}{4 \pi(1-R)^{4}}\left(\frac{\Delta K}{\sigma_{y}}\right)^{4}=C_{0}(\Delta K)^{4}
$$

where $B$ is the specimen thickness, $r_{p}$ is the plastic zone radius, $R$ is the ratio of minimum to maximum load during $F C G, \sigma_{y}$ is the yield strength, and $C_{0}$ is a constant. A simple expression for $\Delta K$ may be written as: 


$$
\Delta K^{2} \approx \Delta \sigma^{2} \pi a
$$

where $\sigma$ is the difference between the maximum and minimum applied stress and $a$ is the crack length. Substitution of Equation (5) into Equation (4) and differentiating leads to the following expression:

$$
d V_{p} \approx 2 \pi C_{0}(\Delta \sigma)^{2}(\Delta K)^{2} d a
$$

Assuming that $\Delta K$ is constant for infinitesimal changes in crack length, and then substituting Equation (6) into Equation (3) and dividing both sides by the number of applied load cycles, $d n$, the following result is obtained:

$$
\mathrm{dN} / \mathrm{dn}=2 \pi \mathrm{C}_{0} \alpha(\Delta \sigma)^{2}(\Delta K)^{2} \mathrm{da} / \mathrm{dn}
$$

This expression may be simplified by substituting the well known empirical equation relating $\mathrm{da} / \mathrm{dn}$ and $\Delta \mathrm{K}$ :

$$
\mathrm{da} / \mathrm{dn}=\mathrm{C}_{1}(\Delta \mathrm{K})^{\mathrm{q}}
$$

where $C_{1}$ and $q$ are constants. Thus, the final equation relating $d N / d n$ and $\Delta K$ is:

$$
\mathrm{dN} / \mathrm{dn} \approx 2 \pi \mathrm{C}_{0} C_{1} \alpha(\Delta \sigma)^{2}(\Delta K)^{2}+q
$$

The second theoretical model, which was originally proposed by Palmer, et. al., $(8,9)$ assumed that the number of $A E$ events produced depends upon the change in crack tip plastic zone size rather than volume. This assumption may be expressed as:

$$
d N=B d S_{p}
$$


where $\beta$ is considered to be a constant of proportionality depending on strain rate, temperature and microstructure. The linear elastic approximation for the plastic zone size is commonly taken to be:

$$
S_{p} \approx 2 B \pi r_{p}=C_{2}(\Delta K)^{2}
$$

where $C_{2}$ is a constant composed of terms defined above. Following a development similar to that used for the plastic zone volume derivation, another result is obtained for $\mathrm{dN} / \mathrm{dn}$ :

$$
d N / d n \approx \pi C_{1} C_{2} \beta(\Delta \sigma)^{2}(\Delta K)^{q}
$$

The last model that was reviewed is from Sinclair, et al. (10) This model is very interesting because of the experimental results that Sinclair, et a1. used to support their theory. The AE data was obtained on A533B steel during FCG. In addition, the AE monitoring system utilized multisensor source isolation techniques to restrict the data to only those signals that originated in the vicinity of the flaw, and event count rather than ringdown count were measured. The methods used to obtain the AE were nearly equivalent to the techniques employed at PNL. The only significant difference was that Sinclair, et. al. used a voltage-controlled gate to restrict the detected emissions to those occurring during $80 \%$ of the upward part of the load cycle.

The basic assumption behind the model is that the total number of emission events, $\mathrm{N}$, detected during cyclic loading in which fatigue crack area, $A$, is created is directly proportional to that area. In differential form this assumption may be expressed as:

$$
\mathrm{dN}=\gamma \mathrm{dA}
$$

where $Y$ is defined as the specific emission activity for FCG in the material under test. Since $d A$ is equivalent to Bda we may rewrite Equation (13) to read:

$$
d N=B r d a
$$


Dividing both sides of Equation (14) by $d n$ and substituting for $d a / d n$, we have:

$$
\mathrm{dN} / \mathrm{dn}=\mathrm{BrC}_{1}(\Delta K)^{\mathrm{q}}
$$

Theoretical equations relating surmation $A E(\Sigma N)$ to $\triangle K$ may be simply derived by integrating Equations (3), (10), or (13) for each respective model. A summary of the theoretical predictions and experimental results obtained from rate and summation analyses of several specimens is listed in Table 4. The total valid unpartitioned $A E$ count was used for calculating the experimental $d N / d n-\Delta K$ and the $\Sigma N-\Delta K$ curves. In general, the compact tension rate data agree with the behavior predicted by the plastic zone and crack area models. The room temperature SEN rate data agree with the plastic zone and crack area models, but the $550^{\circ} \mathrm{F}$ SEN rate data agree with none of the models. In regard to the summation analysis predictions, none of the experimental results matched the theoretical calculations.

The reasons for the general lack of agreement between the theoretical and experimental calculations may, in part, be due to a breakdown of linear elastic fracture mechanics when applied to AE monitoring. Since fracture mechanics variables are based upon continuum mechanics concepts without regard to the microstructural nature of the material, it is not surprising to find

TABLE 4. Summary of AE-FCG Rate and Summation Analyses for Several Specimen Geometries and Material Conditions

\begin{tabular}{|c|c|c|c|c|}
\hline & $\begin{array}{l}\text { Plastic } \\
\text { Zone } \\
\text { Volume } \\
\end{array}$ & $\begin{array}{l}\text { Plastic } \\
\text { Zone } \\
\text { Size } \\
\end{array}$ & $\begin{array}{l}\text { Crack } \\
\text { Area } \\
\end{array}$ & $\begin{array}{l}\text { Experimental } \\
\text { Results } \\
\end{array}$ \\
\hline $\begin{array}{l}\text { Rate } \\
\mathrm{dN} / \mathrm{dn} . \propto\end{array}$ & $\Delta k^{q+2}$ & $\Delta K^{q}$ & $\Delta K^{q}$ & $\Delta K^{2.4-4.8}$ \\
\hline Immation & & & & \\
\hline$\sum N \propto$ & $\Delta K$ & $\Delta K$ & $\Delta K$ & $\Delta K$ \\
\hline
\end{tabular}

NOTE: The exponent $q$ is the exponent for the $d a / d n-\Delta K$ power- law relation, and is typically in the range of 2.3 to 2.8 for values of $\Delta K$ between 20 and 100 ' ksi $\sqrt{\text { in. }}$ 
that attempts to correlate microscopic failure events (AE) with macroscopic measurements (i.e., loading state, crack length, COD, etc.) may only be partially successful. In addition, using the total valid unpartitioned $A E$ count obtained from the entire load cycle may not be valid.

The possible combination of crack extension and crack closure emissions may tend to complicate analysis of the results. The data published by Sinclair, et al. ${ }^{(9)}$ seem to indicate that this hypothes is has some merit. Part of the effort for FY-79 will concentrate on partitioning the AE with respect to position on the load waveform. Most likely this work will aid in clarifying the situation. 


\section{RECOMMENDATIONS FOR FUTURE WORK}

Discussion of further development work is categorized relative to general program objectives.

\section{AE/FLAW MODEL DEVELOPMENT}

We feel that the two empirical models discussed in the preceding section demonstrate that an interpretive model is feasible. Although we recognize that the models are not yet adequately refined for application, it is important at this time to verify that the same response pattern can be observed under conditions simulating the major factors associated with on-reactor monitoring. Evident factors that require definition or further confirmation are the effects of load cycle rate, R-ratio, (minimum load/ maximum load), simulated service loading, material volume, water and temperature.

The effect of load cycle rate is vital to determining if the denominator in the AE rate/crack growth rate model can be converted from load cycles to the more tractable parameter of time for inservice monitoring.

For practical reasons, FCG testing to date has been performed at low R-ratios. Since much of the cyclic loading on a reactor system will be at high R-ratio, it is necessary to now confirm whether this will influence the $\mathrm{AE} / \mathrm{flaw}$ models.

Closely allied with consideration of high R-ratio is consideration of simulated reactor service loading. FCG studied so far on this program has been generated by constant amplitude sinusoidal cyclic loading. Testing which attempts to simulate service loading is needed to determine if this influences the AE/fracture mechanics relationship. Such a test might incorporate monotonically increasing load with a high R-ratio cyclic load superimposed during a prolonged hold at load, removing all load for a period, and then repeating the cycle.

Limitations of test equipment capacity have 1 imited FCG testing to thicknesses of 1 to $2 \mathrm{in.}$ Limited insight as to the effect of greater material 
volume on detected AE has been gained from monitoring two HSST test vessels (6-in. wall) during fracture testing. Both vessel tests showed more AE in the elastic region than have laboratory fracture tests. Similar interfacing with other programs performing heavy section testing (preferably FCG should continue.

Comparison of results from laboratory fracture tests and HSST vesse] tests shows tentative indication of a flaw geometry effect. An SN lab specimen test compared more closely with the vessel tests than did lab specimens using a through-wall notch. Further investigation of flaw geometry effect is planned using SN FCG specimens.

Empirical results concerning temperature effects on $A E$ are inconsistent. Laboratory FCG tests have shown a reduction in $\mathrm{AE}$ in going from room temperature to $550^{\circ} \mathrm{F}$. Conversely, HSST vessel and SN fracture tests showed effectively no effect on $A E$ relative to fracture mechanics comparing $-5^{\circ}$ with $+200^{\circ} \mathrm{F}$. This inconsistency must be resolved.

Similarly, one FCG test of water effects using an immersed specimen showed a reduction in $A E$ associated with immersion in water. Due to multiple possible causes, this result is not conclusive. Since fatigue cracks in a reactor vessel may be exposed to water, this question must be answered positively.

A test of path dependence during $F C G$, i.e., decreasing versus increasing $\Delta K$, is planned as one test of the validity of the present $A E / f l a w$ model.

A test is needed to verify that the present $A E / f 1$ aw model is discernable under the major conditions present in reactor monitoring. This may take the form of a cylindrical test specimen with an inside flaw exposed to pressurized, high-temperature water. The flaw would be grown by cyclic loading at low- and high-cycle rates and R-ratios.

\section{AE SIGNAL CHARACTERIZATION}

As discussed earlier in this report, work to date in the area of $A E$ signal characterization to distinguish AE from other acoustic signals has not produced the results desired. It is vital that progress in this area be 
emphasized. Two general avenues of investigation are planned. Using a recently assembled computer data analysis system, we plan a more rigorous analysis of the measured AE parameters. This includes such parameters as energy, a modified peak-time and peak-amplitude measure, and first half-cycle polarity. Also, a new parameter is now available for FCG studies. This consists of identifying the time location of each valid AE signal with respect to the load waveform. This offers new potential for relating to the details of FCG and identifying the possible contribution of crack interface noise to the total AE measured from a growing crack.

A second avenue of investigation is to further explore pattern recognition techniques for identifying AE signals. Recent work applying pattern recognition to eddy current and ultrasonic signals and a very limited sample of $A E$ signals has produced encouraging results. We plan to collect samples of valid AE signal waveforms in digital form during crack growth, slag inclusion and oxide tests. Samples of known and identified noise signals (tapping and rubbing on the specimen and electrical transients, etc.) will also be provided. These will then be examined by pattern recognition techniques for distinguishing features.

\section{DATA ACQUISITION SYSTEM}

The $A E$ sensor is obviously the key element in a data acquisition system. High-temperature AE sensors have been tested in the laboratory for nearly a year. At least one sensor shows good resistance to temperature exposure $\left(550^{\circ} \mathrm{F}\right.$ and $\left.288^{\circ} \mathrm{C}\right)$. Testing now needs to be expanded to actual reactor environment (temperature, humidity and radiation exposure).

\section{APPLICATION DEMONSTRATION}

Two interrelated efforts are required in preparation for demonstration of program results. One of the efforts concerns development and design of an optimized on-reactor AE data acquisition system. Considerations to be taken into account include: 
- total volumetric monitoring versus selected area (welds, nozzles, etc.) monitoring

- $A E$ source determination method, i.e., identify an area by source isolation, a resolution element pattern using "look-up" tables in a computer, or point source determination on each signal

- data recording and readout method.

Related to the data acquisition system design is design of a methodology for application of an interpretive model in the field. This will have a direct bearing on design of the data processing portion of the data acquisition system.

A minimum of about two years of on-reactor monitoring will be required to demonstrate the results of this program and overcome practical problems expected to surface during such a test phase.

\section{DETERMINATION OF AE SOURCE MECHANISMS}

Although it is outside the scope of this program, investigation of $\mathrm{AE}$ source mechanisms could aid the development of analytical relationships between $A E$ detected during structural FCG and the severity of the flaws producing $A E$. Such investigations could provide a basis for selecting appropriate engineering parameters for use in model development.

Additionally, this work could provide a means for making rational predictions on conditions that might occur on a structure, but which were not tested in the laboratory. Laboratory experiments, as a matter of economics, cannot test all possible combinations of variables (e.g., R-ratio, cycle rate, radiation effects and water pressure and temperature) which might influence the $A E$ during reactor operation. However, when theoretical concepts are merged with appropriate experimental measurements the "gaps" in the data are closed.

In addition, such work might also shed some light on the nature of basic deformation and fracture events that accompany subcritical crack initiation and propagation. Although much work has been done in this area there is still relatively little known about the micromechanics of these processes. 


\section{REFERENCES}

1. Hutton, P. H, C. B. Schwenk, R. J. Kurtz and C. Pavloff. Acoustic Emission--Flaw Relationships for In-Service Monitoring of Nuclear Pressure Vessels. Annual Report No. 1, NUREG 0250-3, BNWL-2232-3, Pacific Northwest Laboratory, Richland, WA.

2. Hutton, P. H., J. F. Dawson and R. J. Kurtz. 1978. Appendix B in Test of Six-Inch-Thick Pressure Vessels, Series 3: Intermediate Test Vessel V-78. NUREG/CR-0309, ORNL/NUREG-38, Oak Ridge National Laboratory, Oak Ridge, TN.

3. Hutton, P. H., E. B. Schwenk and R. J. Kurtz. 1979. "Acoustic Emission--Flaw Relationships for In-Service Monitoring of Nuclear Pressure Vessels." In Reactor Safety Research Programs Quarterly Report, Ju ly 1--September 30,1978. NUREG/CR-0546, PNL-2653-3, Pacific Northwest Laboratory, Richland, WA.

4. Morton, T. M., R. M. Harrington and J. G. Bjeletich. 1973. Eng. Frac. Mech., $\underline{5}: 691$.

5. Harris, D. 0, and H. L. Dunegan. 1974. Exp. Mech., 14:71.

6. Morton, T. M., S. Smith and R. M. Harrington. 1974. Exp. Mech., $\underline{14: 208 .}$

7. Lindley, T. C., I. G. Palmer and C. E. Richlard. 1978. Matl. Sci. Eng., $\underline{32: 1 .}$

8. Palmer, I. G. and P. T. Heald. 1973. Mat1. Sci. Eng., 11:181.

9. Palmer, I. G. 1973. Mat1. Sci. Eng., 11:227.

10. Sinclair, A. C. E. , D. C. Connors and C. L. Formby. 1977. Mat1. Sci. Eng., 28:263. 
NUREG/CR-0800

PNL-2977

R5

\section{DISTRIBUTION}

No. of

Copies

\section{OFFSITE}

A. A. Churm

DOE Chicago Patent Group

9800 S. Cass Avenue

Argonne, IL 60439

265 Basic Distribution Under NRC R5

2 DOE Technical Information Center

25 National Technical Information Service

10 J. Muscara

Reactor Safety Research Division

Nuclear Regulatory Commission

Washington, DC 20555

2 Electric Power Research Institute 3212 Hillview Avenue

P.0. Box 10412

Palo Alto, CA 94304

L. Agee

B. R. Sehgal

F. Shakir

Department of Metallurgy

Association of American Railroads

3140 S. Federa?

Chicago, IL 60616

SM-ALC/MMET

Attn: Capt. John Rodgers

McClellan AFB, CA 95652

Dr. Sotirios J. Vahaviolos

Western Electric, ERC

P.0. Box 900

Princeton, NJ 08540
Mr. Jerry Whittaker

Union Carbide Company

Oak Ridge National Laboratories

$\mathrm{Y}-12$

Oak Ridge, TN 37830

Mr. L. J. Anderson, B2402

Dow Chemical Company

Texas Division

P.0. Drawer K

Freeport, TX 77541

Mr. M. C. Jon

Western Electric, ERC

P.0. Box 900

Princeton, NJ 08540

P. Causs in

Vincotte

1640 Rhode-Saint-Genese

Belgium

143 U.S. Acoustic Emission Working Group Membership - labels attached.

Don Birchon

Admiralty Materials Laboratory

Holton Health Poole

Dorser, Engl and

020-122-2711 


\section{$\underline{\text { ONSITE }}$}

\section{Pacific Northwest Laboratory}

J. F. Dawson

A. J. Haverfield

J. L. Hooper

P. H. Hutton (15)

R. J. Kurtz

R. T. Landsiede 1

R. P. Marshall

R. D. Nelson

N. J. Olson

G. J. Posakony

E. B. Schwenk (2)

J. R. Skorpik

Technical Information (3)

Publishing Coordination (2) 